\title{
Agent-based modeling and simulation to assess flood preparedness and recovery of Manufacturing Small and Medium-sized Enterprises
}

\author{
Graham Coates $^{1 *}$, Chunhui Li ${ }^{2}$, Sangaralingam Ahilan ${ }^{3}$, Nigel Wright ${ }^{4}$, Meshal Alharbi² \\ ${ }^{1}$ School of Engineering, Newcastle University, United Kingdom. \\ ${ }^{2}$ School of Engineering and Computing Sciences, Durham University, United Kingdom. \\ ${ }^{3}$ School of Civil Engineering, University of Leeds, United Kingdom. \\ ${ }^{4}$ School of Engineering and Sustainable Development, De Montfort University, United Kingdom. \\ *Corresponding author: graham.coates1@newcastle.ac.uk
}

\begin{abstract}
Severe flooding has caused major damage and disruption to households, communities, businesses, and organizations in many parts of the world. In the United Kingdom (UK), flooding has been responsible for significant losses to the economy due to its impact on businesses, $99.9 \%$ of which are Small and Medium-sized Enterprises (SMEs). This paper reports on how agent-based modeling and simulation has been developed and used to assess the effectiveness of a range of physical/structural and social preparedness adaptation measures that can be implemented by manufacturing SMEs to reduce the impact of and expedite recovery from a major flood event. Results indicate the effectiveness of combinations of these adaptation measures in relation to a one in 1000 year flood event that has been modeled and simulated in a key industrial area of the UK which, in addition to having experienced severe flooding, has a high concentration of SMEs.
\end{abstract}

Keywords: Agent-based modeling/simulation; Flood preparedness/recovery; SMEs.

\section{Introduction}

\subsection{Flooding and businesses}

Recent years have seen many parts of the world suffer from severe flooding which continues to cause significant damage and disruption to households, communities, businesses and organizations. In the United Kingdom (UK), flooding is the most common and widespread natural disaster (Environment Agency, 2017) and recognised in the National Risk Register of Civil Emergencies as a key risk (The UK Cabinet Office, 2015). Flooding can be devastating to businesses, especially Small and Mediumsized Enterprises (SMEs) (G. Wedawatta, Ingirige, \& Proverbs, 2014), which have experienced significant losses in terms of damage to property and disruption to operations. For example, in terms of financial losses, the Environment Agency has estimated that 7100 to 8000 businesses were affected by the 2007 summer floods in England at a cost of $£ 740$ million; $£ 580$ million damage and $£ 160$ million disruption (John Chatterton, Viviattene, Morris, Penning-Rowsell, \& Tapsell, 2010). Also, the 2013/14 winter floods in England and Wales have been reported as affecting between 3139 and 
4897 businesses at a cost of $£ 271$ million ( $\mathrm{J}$ Chatterton et al., 2016). Further, it has been estimated that flood damage could account for $£ 10$ billion to the UK economy in 25 years (Confederation of British Industry, 2009) and that risks relating to precipitation, over the next 30 to 100 years, will increase by two to four times across the UK, with some locations experiencing changes beyond this range (Evans et al., 2008). Such significant actual and projected economic losses have led to flood risk management becoming high on the political agenda. Consequently, means of reducing the economic impact of damage and disruption caused by flooding at the business level, and more widely, are receiving growing attention.

Effective business continuity management $(B C M)$ is recognised as a means of reducing the effect of flooding on business operations (Best \& Fraser, 2009), especially SMEs (Sterling, 2011), and enabling a more rapid return to normality. Further, BCM is viewed as a key part of any successful flood response (Pitt, 2008) and, more generally, an important tool for business survival in the face of a range of disruptive events (Herbane, 2010b). The International Organization for Standardization's ISO 22301 , which relates to $B C M$, is described as the requirements which will help organizations better prepare for and handle disruptions of any type (British Standards Institution, 2012). Despite the existence of such standards, in the UK, organizational engagement with business continuity remains low with less take up by SMEs relative to larger businesses and public sector bodies (Herbane, 2010a; Ingirige \& Wedawatta, 2011a). This is of particular relevance given that the impact of flooding is arguably more acutely felt by SMEs due to their lack of organizational resilience in the face of such disruptive events (McGuinness \& Johnson, 2013; Reuter, 2015). Indeed, SMEs can suffer significant financial losses as a consequence of a disruption to business operations caused by flooding due to having limited resource (Sullivan-Taylor \& Branicki, 2011; Van Gils, 2005), no organizational slack (Grunert \& Norden, 2012), and a lack of formal contingency/disaster recovery plans (Jones \& Ingirige, 2008; Li, Coates, Johnson, \& Mcguinness, 2015), all of which diminish the effectiveness and efficiency of recovery. Furthermore, it has been reported that "SMEs often tend to underestimate the risk of flooding which tends to have a low priority in their business agenda" (Gayan Wedawatta \& Ingirige, 2012).

SMEs are of particular importance to the UK economy as they account for $99.9 \%$ of private sector businesses, approximately $60 \%$ of employment and $47 \%$ of annual turnover (Rhodes, 2016). Table 1 presents a breakdown of these figures according to SME size which can be classified according to number of employees and turnover or balance sheet total; however, it is noted that this classification can vary from one country to another. For the UK, in terms of number of employees, micro businesses have less than 10, small sized have greater than or equal to 10 but less than 50 , and medium-sized have greater than or equal to 50 but less than 250 . As can be seen in Table 1, microsized businesses dominate in terms of proportion of SMEs, employment and turnover.

\begin{tabular}{|l|c|c|c|}
\hline SMEs & Businesses (\%) & Employment (\%) & Turnover (\%) \\
\hline Micro (1 to 9 employees) & 95.6 & 32.5 & 18.6 \\
\hline Small (10 to 49 employees & 3.7 & 15.2 & 14.5 \\
\hline
\end{tabular}




\begin{tabular}{|l|c|c|c|}
\hline Medium (50 to 249 employees) & 0.6 & 12.4 & 14.1 \\
\hline Total & $\mathbf{9 9 . 9}$ & $\mathbf{6 0 . 1}$ & $\mathbf{4 7 . 2}$ \\
\hline
\end{tabular}

Table 1: Breakdown of private sector SMEs in the UK (Rhodes, 2016)

Given the predominance of SMEs and their significance to the economy, coupled with the fact that these businesses are generally ill-prepared to cope with disruptive events such as flooding, the research presented in this paper is aimed at assessing the ways in which they could better prepare for and recover from flooding thus making them more resilient.

\subsection{Modeling SMEs' flood preparedness, response and recovery}

Research is lacking in modeling how SMEs prepare for, respond to and recover from disruptive events such as flooding. In relation to flooding, SMEs' behaviour in response and recovery are complex processes involving a range of other businesses and organizations, thus requiring a suitable modeling approach. One such approach is agent-based modeling which has received increasing attention in recent years to facilitate the study of complex processes and systems in a range of diverse fields such as biology, business and social science (Heath, Hill, \& Ciarallo, 2009; M. J. North \& Macal, 2007). Indeed, agent-based simulation models have been highlighted as a means of gaining an understanding of business relations and networks (I. Wilkinson, Marks, \& Young, 2010) and reproducing the interactions between different organizations in an artificial environment (Fioretti, 2013). Further, it has been asserted that, unlike traditional static data capture and analysis methods, agent-based simulation models enable systematic investigations into the dynamic and evolutionary nature of business relations and networks (I. F. Wilkinson, Young, Marks, Bossomaier, \& Held, 2011).

In the disaster management domain, research in the area of agent-based modeling and simulation (ABMS) has focused on the emergency response to major natural and manmade events with agents representing individuals exhibiting behaviour intended to mimic emergency responders and/or members of the public (Bellamine-Ben Saoud, Ben Mena, Dugdale, Pavard, \& Ben Ahmed, 2006; Hawe, Coates, Wilson, \& Crouch, 2015; Hooshangi \& Alesheikh, 2018; Mysore, Narzisi, \& Mishra, 2006). In the context of flood risk management, agent-based models (ABMs) have been used to model evacuation strategies involving agents representing individual members of the public (Dawson, Peppe, \& Wang, 2011; Liu, Okada, Shen, \& Li, 2010). In addition, ABMs have been utilised to evaluate flood communication strategies on individuals (Haer, Botzen, \& Aerts, 2016), analyse the influence of individual behaviour on community flood risk (Tonn \& Guikema, 2017), investigate the role of individuals' use of social media in relation to flood evacuation (Du, Cai, Sun, \& Minsker, 2017), assess individual household flood response preferences (Yang, Scheffran, Süsser, Dawson, \& Chen, 2018) and examine the dynamic evolution of flood risk and vulnerability of homeowners (Dubbelboer, J., Nikolic, J., Jenkins, K., Hall, 2017; Jenkins, Surminski, Hall, \& Crick, 2017) 
In terms of modeling businesses, a recent survey of the use of agent-based simulation in management and organizational studies revealed the highest number of applications being in the areas of operations and logistics, marketing and organizational behaviour (Gómez-Cruz, Loaiza Saa, \& Ortega Hurtado, 2017). Beyond the areas reported in this survey, agent-based approaches have been used to study business related issues such as the dynamic formation of supply chains (Wang, Wang, Vogel, Kumar, \& Chiu, 2009), cost collaborative management in supply chains (Fu \& Fu, 2015) and the collaboration duration of supply chains (Arvitrida, Tako, Robertson, \& Robinson, 2017). Specifically in relation to SMEs, ABMs have been used to model their evolution (Blackmore, Bossomaier, Jarratt, \& Nesbitt, 2003), study their supply chains (Tounsi, Habchi, Boissiere, \& Azaiez, 2012), assess their resilience (Sauser, Baldwin, Pourreza, Randall, \& Nowicki, 2017) and predict the impact of public policies on them (Pablo-Marti, Gallo, Garcia-Tabuenca, Santos, \& T. Mancha, 2012). For example, an ABM has been used to assess the relationship between the resilience of SMEs postdisaster and community recovery (Sauser et al., 2017). With resilience summarised as maintaining business continuity, results presented indicate that a linear relationship exists between disaster severity and impact to the community (the number of SME closures) until more than half of the community is damaged, at which point it cannot recover.

Despite the research conducted on ABMs of SMEs, allied with discussions of the notion of using such models in business and organization problems (Bonabeau, 2002; Dignum \& Tick, 2007; Fioretti, 2013; M. J. North \& Macal, 2007; I. Wilkinson et al., 2010), research to date in terms of preparing for, responding to and recovering from disruptive events, in particular flooding, remains unexplored. The current dearth of research in ABMS of SMEs in the context of flooding, coupled with the limited work undertaken to date in understanding how SMEs currently deal with extreme weather events (Bhattacharya-Mis \& Lamond, 2014; Ingirige \& Wedawatta, 2011b), presents a significant research challenge. More specifically, in relation to flooding, there exists scope to develop and utilise agentbased modeling and simulation to represent and study SMEs' behaviours pre, during and post-flood. Additionally, in the modeling process, there is an opportunity for close SME involvement to enable realistic behaviours to be captured and embedded within ABMs developed.

\subsection{Contribution of this paper}

Recognising the lack of models of SMEs dealing with disruptive events, the research reported in this paper is aimed at developing and using ABMS, coupled with flood modeling and simulation, to evaluate SMEs' preparedness and recovery in relation to significant flood events, with a focus on businesses from the manufacturing sector. Through modeling and simulation, this research aims to: (i) identify the specific SMEs affected by a significant flood event in a particular geographical area; (ii) model manufacturing SMEs as agents' with behaviours relevant to responding to and recovering from a flood event based on data gathered from semi structured interviews with over one hundred SMEs at risk of flooding and/or with experience of flooding; (iii) perform what if analysis via agent-based simulation of SMEs leading up to and in the short term aftermath of a flood event to assess the effect 
on recovery of a range of different combinations of preparedness adaptation measures, both physical/structural and social. In achieving this aim, the research will inform manufacturing SMEs which adaptation measures, and combinations thereof, offer an effective means of reducing the damage and disruption associated with flooding thus strengthening their organizational resilience to such events.

The remainder of this paper is organized as follows. Section 2 provides a brief overview of the modeling and simulation framework which forms part of the SESAME flood risk management project aimed at informing organizational resilience (Coates et al., 2013). Following this, Section 3 presents the framework's flood modeling and simulation component in the context of a case study related to the severe flooding in 2007 of Sheffield's Lower Don Valley in the UK. Section 4 presents the framework's ABM and Section 5 discusses agent-based simulation results. Finally, the conclusions of the research and area for future work are summarised in Section 6.

\section{Overview of the modeling and simulation framework}

A modeling and simulation framework has been developed to facilitate investigations into how flood preparedness adaptation measures implemented by manufacturing SMEs could influence the continuity of their business operations when faced with a flood event. As indicated in Figure 1, the framework consists of three components: (i) flood modeling and simulation; (ii) a virtual geographic environment (VGE); (iii) ABMS.

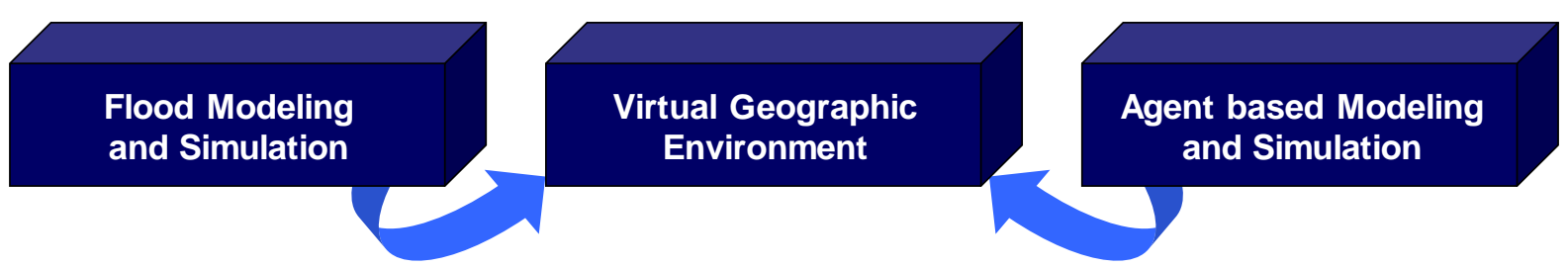

Figure 1: Three components of the modeling and simulation framework

Flood modeling and simulation is discussed in Section 3 and ABMS is described in Sections 4 and 5. The VGE component facilitates the link between the flood event modeled/simulated and the ABMS of manufacturing SMEs. The VGE has been developed using layers from Ordnance Survey's MasterMap $^{\oplus}$, namely the Topography Layer, Integrated Transport Network ${ }^{\mathrm{TM}}$ (ITN) Layer and Address Layer. For any given geographical area: the Topography Layer includes information on individual buildings including business premises; the ITN Layer consists of information related to the road network; the Address Layer contains information regarding commercial properties including coordinates of the precise location along with identification of the associated building in the Topography Layer and adjacent road links in the ITN Layer. The VGE combines with flood modeling and simulation to enable the identification of SMEs' premises affected by flooding throughout the inundation event considered. Details of the flood modeling and simulation component of the framework are provided in the context of the flood event case study presented in Section 3 given these are closely coupled. 


\section{Flood modeling and simulation of a one in $\mathbf{1 0 0 0}$ year flood event in Sheffield, UK}

\subsection{Background}

Flood modeling and simulation is used to generate estimated water depths in all locations of the geographical area under consideration, over the duration of the inundation event, thus providing input to the VGE enabling SMEs affected by flooding to be identified.

In this paper, the Lower Don Valley region of Sheffield has been selected as the case study area. The map of the UK shown in Figure 2(a) indicates the location of Sheffield, which is the $5^{\text {th }}$ most populated city and a highly industrial urban area consisting of businesses from a wide range of sectors. In particular, this area has a high concentration of SMEs. Figure 2(b) shows the VGE representation of the Lower Don Valley used to identify flood affected SMEs.

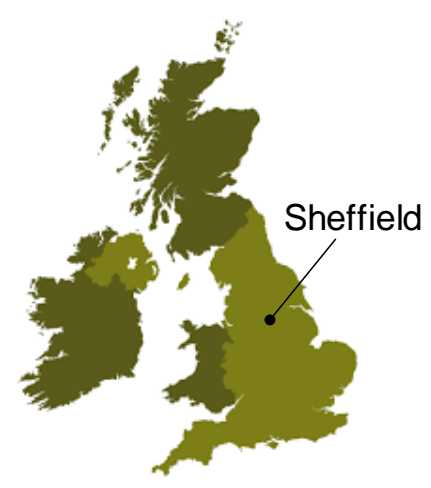

(a)

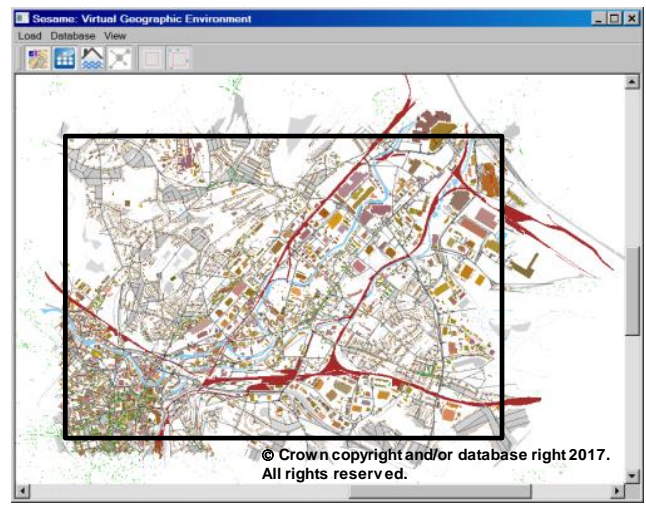

(b)

Figure 2: (a) Location of Sheffield in the UK and (b) Virtual Geographic Environment of the Lower Don Valley

The VGE of the Lower Don Valley presented in Figure 2(b) was constructed using Ordnance Survey's MasterMap ${ }^{\odot}$ data from the Topography, ITN and Address layers for the area defined by eastings and northings of 434720.0, 386937.5 (lower left) and 440210.0, 390837.5 (upper right).

A one in 1000 year flood event has been modeled and simulated in the Lower Don Valley region of Sheffield, including the River Don and its tributaries, as this closely represents the severe flooding experienced in June 2007. Prolonged rainfall, including 100 mm falling in one 24 hour period, followed by the River Don breaching its banks on 25th June caused considerable damage to properties in the Lower Don Valley (Environment Agency, 2011). During the period of precipitation, the return period of total depth of rainfall was approximated to a one in 200 year event. However, saturated soil in the catchment and lack of storage capacity in upstream reservoirs, both of which were caused by 
prolonged rainfall, coupled with culvert blockages in the River Don and its tributaries further exacerbated the scale of flooding leading to a more extreme one in 1000 year event.

\subsection{Methodology}

Flood modeling and simulation has been carried out using a hydrodynamic model that couples a one dimensional (1D) ISIS model and a two dimensional (2D) TUFLOW model, both of which were provided by the Environment Agency. The ISIS model and TUFLOW model were constructed using commercial modeling software developed by $\mathrm{CH} 2 \mathrm{M}$ (www.floodmodeller.com) and BMT Group Ltd (www.tuflow.com) respectively. The ISIS modeling software is used to model flows and water levels in open channels and floodplains, which can include a range of structures (CH2MHILL, 2015). The TUFLOW modeling software is a grid based hydrodynamic free-surface flow solver that enables freesurface computational hydraulics of floods to be performed (TUFLOW, 2016).

In the ISIS model the river channel is divided into virtual lengths or reaches bounded by crosssections (Lin et al., 2006). Within each reach the principle of conservation of mass and Newton's second law of motion are applied to determine water depth and volume flow rate. For mass conservation, any difference between inflow and outflow to a reach leads to an increase or decrease in the water level. For Newton's second law, the forces from friction and gravity are equated to the rate of change of momentum between the upstream and downstream cross-sections. The 2DTUFLOW model assumes a hydrostatic pressure in the vertical direction and therefore zero acceleration vertically. This, in turn, allows for consideration of only water depth and two perpendicular horizontal velocities. These three variables are calculated for each cell in a Cartesian horizontal square grid based on three equations: conservation of mass; Newton's second law in the two perpendicular directions. In this work, the concepts mentioned in relation to the 1D-ISIS model and 2D-TUFLOW model are encapsulated in the software produced by CH2M and BMT Group Ltd respectively.

In the hydrodynamic model used in this research, the 1D ISIS model represents the river channel and structures such as bridges, spillways, conduits, orifices and culverts which exist along the river whereas the 2D TUFLOW model represents flow in the urban environment located on the floodplain. These two models are dynamically linked which allows water level and flow data to be exchanged between the river channel and floodplain throughout a flood simulation. An overview of the flood modeling and simulation methodology is shown in Figure 3. 


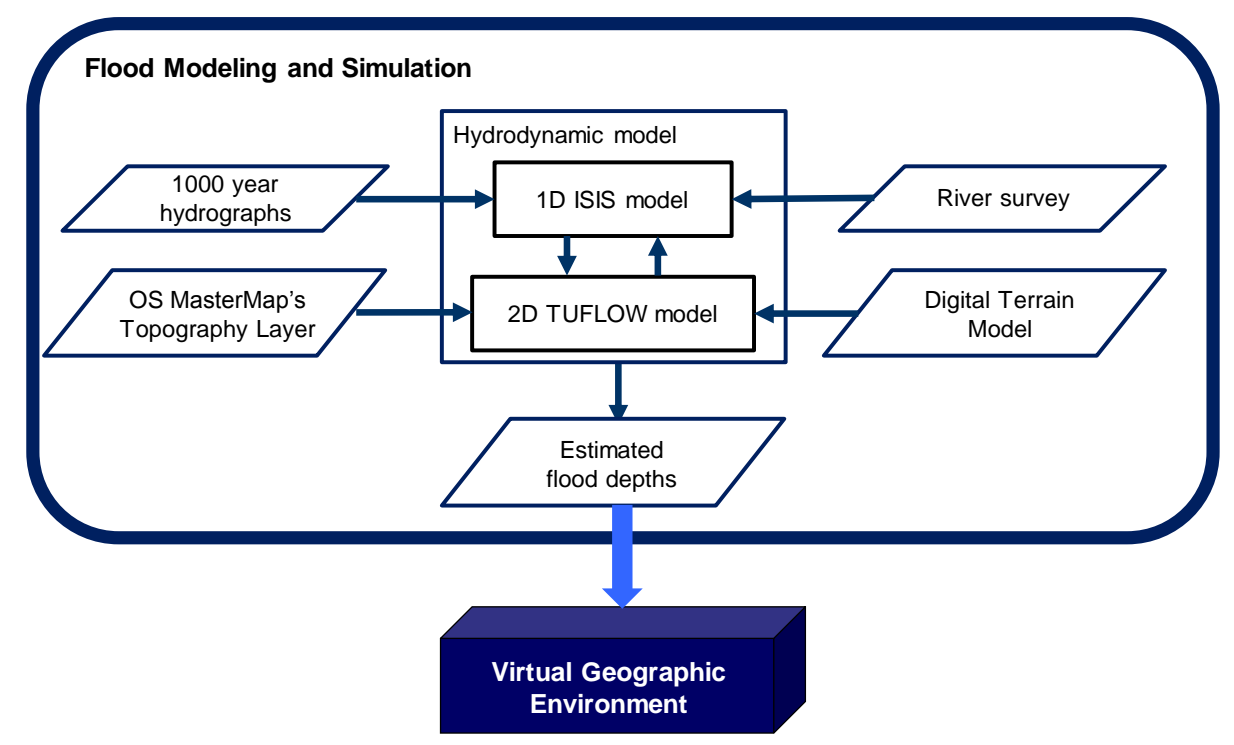

Figure 3: Flood modeling and simulation methodology

The hydrodynamic model has been used to simulate flow propagation of a one in 1000 year flood event in Sheffield's Lower Don Valley using 1000 year hydrographs of the River Don and its tributaries. Furthermore, Ordnance Survey land use data, river channel and floodplain topography data were used to establish flow pathways of the river. More specifically, as indicated in Figure 3, the hydrodynamic model has four input datasets: 1000 year hydrographs, Ordnance Survey MasterMap's Topography Layer, river survey data and Digital Terrain Model (DTM) data.

- 1000 year hydrographs of the River Don and its tributaries were developed for input to the 1D ISIS model upstream of the geographical area being studied. These hydrographs provide a time series of flow over the duration of the flood and were developed in compliance with guidelines produced by the Environment Agency (Environment Agency, 2012). Further, the rainfall duration used to develop the 1000 year hydrographs was determined iteratively using the Revitalised Flood Hydrograph rainfall runoff model (Kjeldsen, Stewart, Packman, Folwell, \& Bayliss, 2005) to find the flood peak value downstream of the River Don in the Lower Don Valley.

- Ordnance Survey MasterMap's Topography Layer data included the building polygons and land use data allowing the assignment of no flow areas around buildings and the application of different surface roughness (based on their resistance to flow) to the land use classes in the 2D TUFLOW model. For example, green parks have a higher surface roughness than concrete areas.

- River survey data provided information regarding the elevation of the river channel and structures along the river in the 1D ISIS model; this data was obtained from a number of field surveys that were undertaken in 2005, 2007 and 2011. 
- DTM data sets from the Environment Agency were used to represent the floodplain's topography, i.e. elevation at regular grid intervals, in the 2D TUFLOW model. The DTM was produced from the Light Detection and Ranging (LiDAR) data sets obtained from an airborne mapping technique that uses a laser to measure the distance between the aircraft and the ground.

The flood simulated has a duration of 45 hours, which includes the 31.5 hour period of rainfall in the River Don catchment, allowing catchment runoff to fully reach downstream urban areas of Sheffield's Lower Don Valley. In terms of output, the hydrodynamic model yields estimated flood depths that form the input for the VGE in which flood affected manufacturing SMEs can be identified and represented as agents. Throughout the 45 hour flood simulated, at half hour intervals, which corresponds to one time step, or tick, in agent-based simulations, flood depths were estimated at 5 meter $(\mathrm{m})$ grid intervals within the geographical study area. These estimations were recorded in ASCII format and fed into the VGE to enable the identification of the SMEs affected by flooding, and to what extent, throughout the flood simulation period. Figure 4 presents screenshots of the VGE for Sheffield's Lower Don Valley showing the simulated flood extents at 9 hour intervals over the 45 hour flood duration.

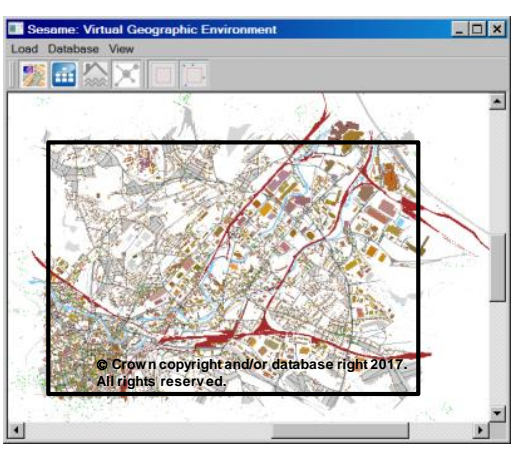

(a) $t=0$ hours

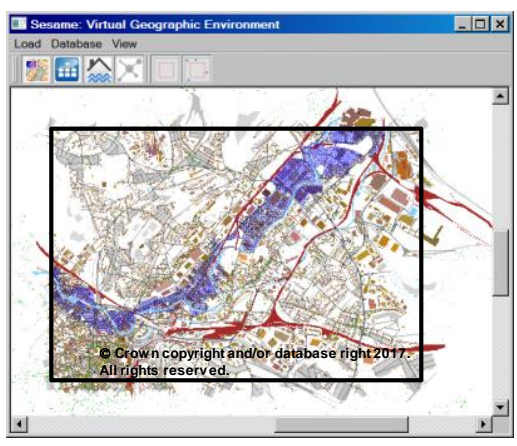

(d) $t=27$ hours

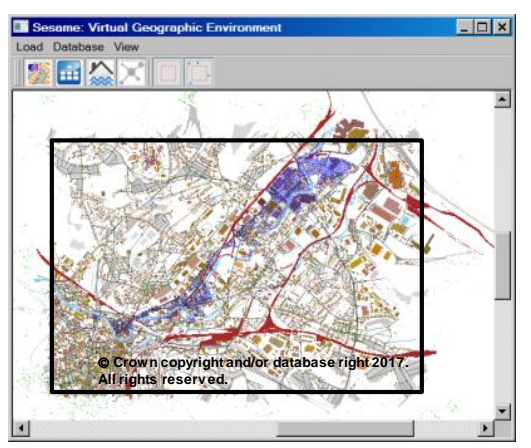

(b) $t=9$ hours

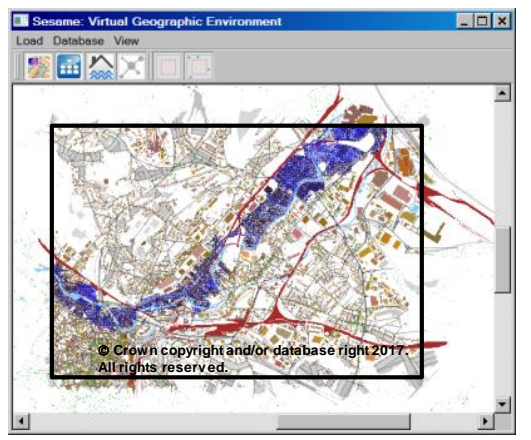

(e) $t=36$ hours

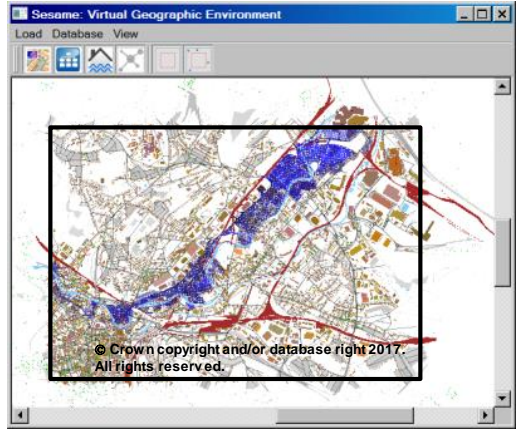

(c) $t=18$ hours

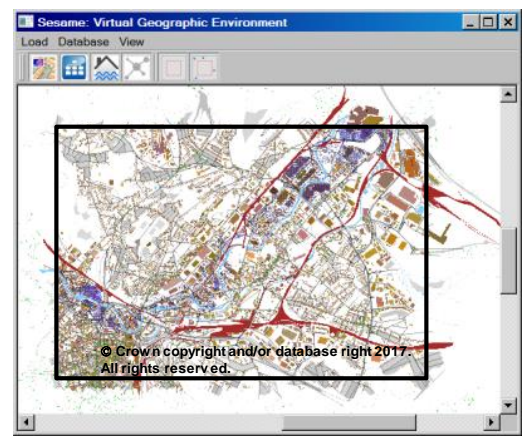

(f) $t=45$ hours

Figure 4: Screenshots of the Virtual Geographic Environment for Sheffield's Lower Don Valley showing the simulated flood extents at 9 hour intervals over the 45 hour flood duration 
For the flood event modeled and simulated, at all locations in the virtual environment, the estimated depths of water at each 30 minute interval over the 45 hour duration represent the exposure to flooding of Sheffield's Lower Don Valley including SMEs' premises and roads adjacent to these buildings. Consequently, in agent-based simulations involving manufacturing SMEs, each of these businesses will enact response and recovery behaviours based on the depth of flood water in and/or around its premises at different times. In Figure 5, in addition to showing the extent of flood water in the VGE for the case study area at time $t=27$ hours as an example, the location of each SME within a small area is indicated using a circle, which is colour coded according to whether their premises is flooded (red), or their premises is not flooded but their associated road link is flooded (orange), or neither their premises or road link is flooded (green).

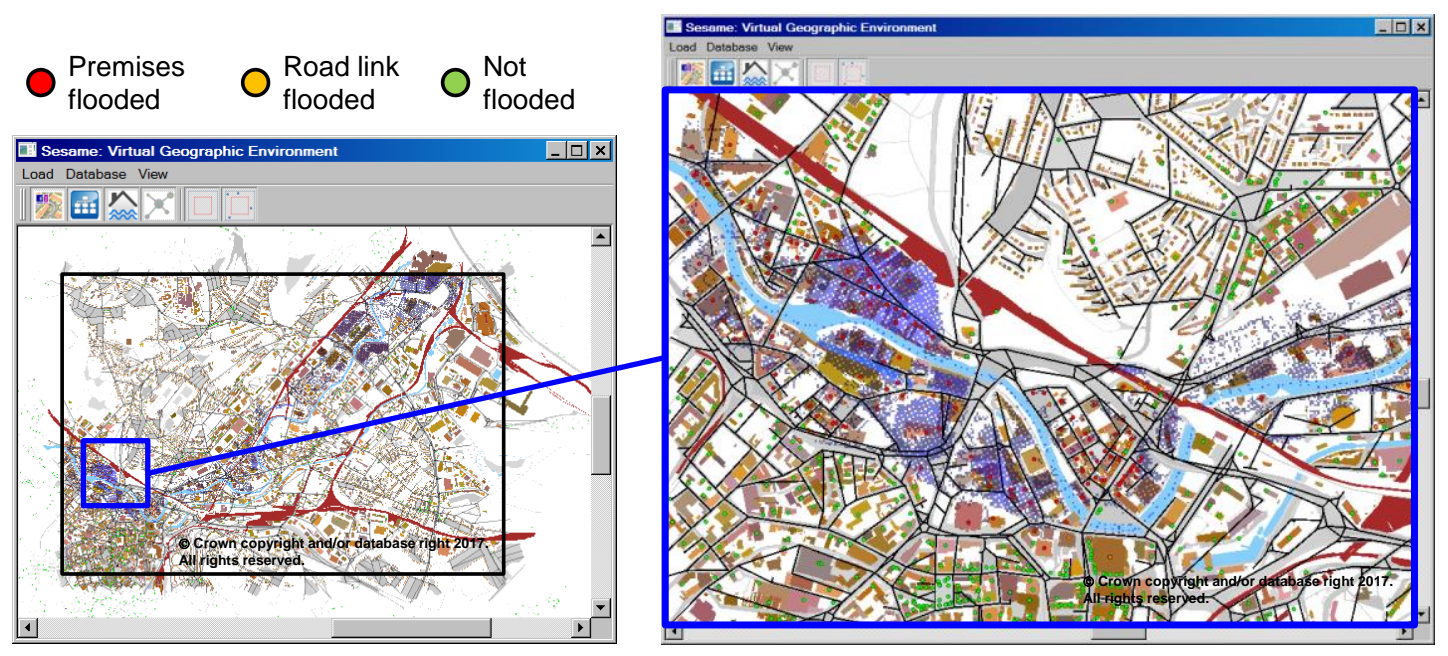

Figure 5: Screenshots of the Virtual Geographic Environment for Sheffield's Lower Don Valley identifying flood affected SMEs at time $t=27$ hours

Within the region of Sheffield's Lower Don Valley considered, based on Ordnance Survey MasterMap's Address Layer, 5570 organizations were identified. Table 2 presents a breakdown of these organizations according to the National Land Use Database Code (NLUD) (Harrison, 2006).

\begin{tabular}{|c|l|l|c|c|}
\hline \multicolumn{2}{|l|}{ National Land Use Database (NLUD) classification } & $\begin{array}{c}\text { Number of } \\
\text { organizations }\end{array}$ & $\begin{array}{c}\text { Percentage of } \\
\text { organizations }\end{array}$ \\
\hline Code & Order & Group & 57 & 1.0 \\
\hline U072 & Residential & Hotels, boarding, guest houses & 116 & 2.1 \\
\hline U081 & Community & Medical and health care services & 72 & 1.3 \\
\cline { 1 - 3 } U082 & \multirow{2}{*}{ Services } & Places of worship & 168 & 3.0 \\
\cline { 3 - 5 } & & Education & 364 & 6.5 \\
\cline { 3 - 5 } U084 & Community services & 2028 & 36.4 \\
\hline U091 & Retail & Shops & & \\
\hline
\end{tabular}




\begin{tabular}{|c|c|c|c|c|}
\hline U092 & & Financial and professional services & 804 & 14.4 \\
\hline U093/94 & & Restaurants, cafes, public houses, bars & 332 & 6.0 \\
\hline U101 & \multirow{3}{*}{$\begin{array}{l}\text { Industry and } \\
\text { Business }\end{array}$} & Manufacturing & 552 & 9.9 \\
\hline U102 & & Offices & 766 & 13.8 \\
\hline U104 & & Wholesale distribution & 94 & 1.7 \\
\hline & & Total & 5570 & \\
\hline
\end{tabular}

Table 2: Classification of organizations in Sheffield's Lower Don Valley using the National Land Use Database Code (Harrison, 2006)

In relation to the 2007 floods in Sheffield, the Environment Agency indicated that "more than 1,000 businesses were affected" (John Chatterton et al., 2010). In close agreement with this number, based on an analysis of the simulated flood event and Ordnance Survey MasterMap's Address Layer using the VGE, 1062 of the 5570 organizations were identified as being affected by flooding at some point during the 45 hour event modeled in Sheffield's Lower Don Valley. In this context, the term 'affected' is used to indicate that flood water entered an SME's premises causing damage and disruption and/or caused roads adjacent to an SME's property to be flooded resulting in disruption. Furthermore, the analysis carried out revealed that 100 SMEs of the 552 manufacturing businesses were affected by the flooding. Consequently, this number of manufacturing SMEs is modeled as agents (Section 4) and simulated to study how different preparedness adaptation measures could potentially alleviate the effect of the flood event considered (Section 5). Importantly, via the VGE, the precise location of each flood affected manufacturing SME's premises has been identified. Knowledge of each of these SME's location is relevant in agent-based simulations since geographical proximity to the River Don is related to the extent and period of flooding experienced and, consequently, how a business may respond to and recover from the event.

\section{Agent-based model}

\subsection{Selection of agent-based modeling and simulation tool/platform}

A number of reviews and surveys of ABMS tools/platforms have been undertaken (Abar, Theodoropoulos, Lemarinier, \& O'Hare, 2017; Allan, 2010; Arunachalam \& Steiner, 2008; Kravari \& Bassiliades, 2015; Nikolai \& Madey, 2009; Railsback, Lytinen, \& Jackson, 2006; Tobias \& Hofmann, 2004). The most recent of these reviews evaluates over eighty ABMS tools in terms of their respective technical features and specifications including model development effort and modeling strength (Abar et al., 2017). Another recent review assesses twenty-four agent platforms against a set of evaluation criteria including usability, operating ability and pragmatics (Kravari \& Bassiliades, 2015). In both reviews mentioned, the evaluation presented is reported as being aimed at providing researchers with information of existing tools/platforms to assist selection. While acknowledging that many ABMS tools/platforms are available, the most widely used are reported to be NetLogo, MASON (Multi-Agent 
Simulation of Neighbourhoods), Repast (Recursive Porous Agent Simulation Toolkit) and Swarm (Railsback et al., 2006). This review is described as providing guidance to potential users of these tools/platforms. Another review included NetLogo, MASON and Repast using assessment criteria related to design, model specification and execution, and documentation (Arunachalam \& Steiner, 2008). Also, Repast and Swarm were considered in a review undertaken using a rating system including criteria such as documentation, support, user base and future viability (Tobias \& Hofmann, 2004).

In the reviews mentioned, each ABMS tool/platform discussed is reported as having benefits and limitations in relation to various criteria. In this paper, given the existence of the reviews undertaken, a summary is given of the key aspects of Repast (Michael J North, Collier, \& Vos, 2006), specifically the Java-based Repast Simphony platform (M J North, 2005; Michael J North et al., 2013), leading to it being chosen to develop and implement the ABMS component of the framework in this research. $A$ key feature of Repast is it was initially developed by social scientists to support applications in that domain (Allan, 2010; Arunachalam \& Steiner, 2008; Railsback et al., 2006). Also, Repast provides demonstration simulation models and new users are supported by a community of model builders (Allan, 2010). Repast has been reported as allowing a large amount of flexibility in the construction of agents and their environment, and thus should be considered seriously to start the journey into agentbased modeling (Robertson, 2005). Repast provides explicit methods for scheduling actions, built-in classes to facilitate output of data to a file, and has the ability to reset and restart models from the graphical interface (Railsback et al., 2006). In particular Repast Simphony enables large-scale simulation application development (Michael J North et al., 2013). Furthermore, Repast Symphony allows running models in 2D and 3D visualisations to be viewed and enables designers to gather and store information from a simulation while it is running; known as data collection.

\subsection{Agent types and relationships}

ABM development has focused primarily on manufacturing SME agents and, in addition, various related types of business and organization albeit to a lesser degree. A number of sources have been used in the development of agents such as transcripts of semi-structured interviews with SMEs, Environment Agency guidance, business continuity management literature and academic literature. In Section 4.4, which presents a validation overview of the ABM developed and its implementation, more information is provided regarding these sources.

Table 3 provides a list of the types of agent modeled and a brief description of each.

\begin{tabular}{|l|l|}
\hline Agent type & Brief description \\
\hline Cleaning contractor & $\begin{array}{l}\text { A service company that undertake a contract to provide a service to aid } \\
\text { the recovery of a manufacturing SME. }\end{array}$ \\
\hline Electrical contractor & $\begin{array}{l}\text { A government funded public body that operates a flood alert/warning } \\
\text { notification service. }\end{array}$ \\
\hline Environment Agency \\
\hline
\end{tabular}




\begin{tabular}{|l|l|}
\hline Insurance company & $\begin{array}{l}\text { A business that can provide a manufacturing SME with insurance cover } \\
\text { against damage to property and equipment, and/or disruption to } \\
\text { business operations due to flooding. }\end{array}$ \\
\hline Manufacturing SME & $\begin{array}{l}\text { A business that manufactures products using raw materials, machines, } \\
\text { and employees; it has less than } 250 \text { employees (a micro-sized SME has } \\
1 \text { to 9; a small-sized SME has 10 to 49; a medium-sized SME has 50 to } \\
249) .\end{array}$ \\
\hline Mutual aid partner & $\begin{array}{l}\text { A business that can provide assistance to a flood affected } \\
\text { manufacturing SME enabling it to continue the manufacture of its } \\
\text { products during the period of disruption. }\end{array}$ \\
\hline $\begin{array}{l}\text { Neighbouring } \\
\text { business }\end{array}$ & $\begin{array}{l}\text { A business located in close geographical proximity to a manufacturing } \\
\text { SME. }\end{array}$ \\
\hline Non-priority customer & $\begin{array}{l}\text { A business or organization that places orders infrequently to purchase a } \\
\text { low proportion of products made by a manufacturing SME. }\end{array}$ \\
\hline Priority customer & $\begin{array}{l}\text { A business or organization that frequently and regularly places orders to } \\
\text { purchase a high proportion of products made by a manufacturing SME. }\end{array}$ \\
\hline Supplier & $\begin{array}{l}\text { A business that provide manufacturing SMEs with raw materials needed } \\
\text { to make products. }\end{array}$ \\
\hline
\end{tabular}

Table 3: Types of agent

In this research, while the focus is on modeling manufacturing SME agents, the other types of business and organization listed in Table 3 have also been modeled given that interactions which a manufacturing SME has with them can directly influence its recovery and performance post-flood. For each manufacturing SME, Figure 6 indicates the communication links with other agents, which is bidirectional.

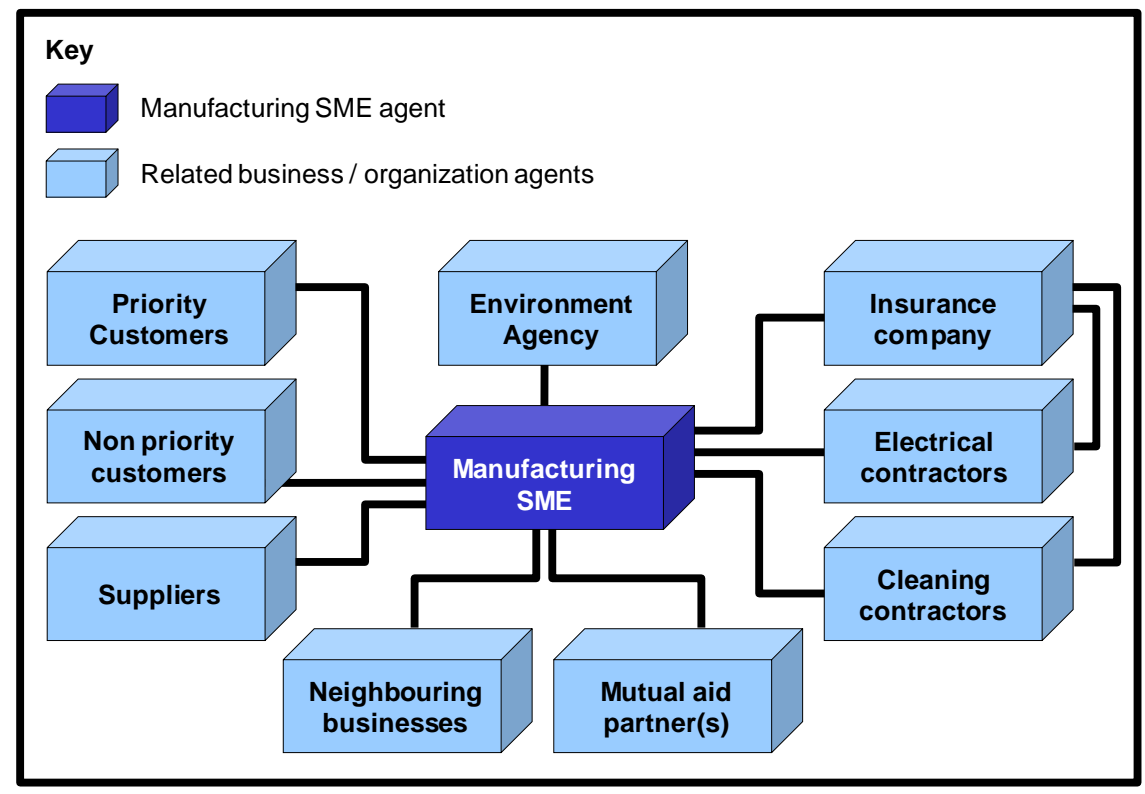

Figure 6: Types of agents modeled and communication links between them 
As indicated, the primary type of agent modeled is a manufacturing SME agent, details of which are discussed in Section 4.3 in terms of (i) attributes, (ii) pre-flood response and post-flood recovery behaviours, (iii) preparedness adaptation measures and (iv) performance metric. Related businesses and organizations modeled as agents are now described briefly in the context of their relationship with a manufacturing SME agent.

- Environment Agency: Prior to a flood event, or a potential flood event, this government funded public body will issue alerts/warnings to manufacturing SMEs that have registered to receive them. Receipt of a flood alert/warning, if trusted, may cause a manufacturing SME to respond pre-flood by enacting behaviours such as moving or raising equipment and/or materials so that they cannot be damaged should flood water enter its premises.

- Contractors: Pre-existing relationships may exist between a manufacturing SME and contractors, i.e. electrical contractors and cleaning contractors, which can speed up their attendance at a manufacturing SME's premises after a flood event and, as a result, shorten the length of business disruption and accelerate the resumption of operations. Alternatively, contractors may attend speedily if requested to do so by a manufacturing SME's insurance company, providing cover is sufficient. In contrast, a manufacturing SME without a preexisting relationship, or sufficient insurance cover, would attempt to contact contractors directly at a time when demand for their services is high meaning they may not be available as soon as needed. Furthermore, when contractors do attend, their service may be interrupted should an SME with a pre-existing relationship, or sufficient insurance cover, subsequently request their assistance.

- Customers: These businesses and organizations are classified as priority customers or nonpriority customers, where the former frequently and regularly places orders to purchase a high proportion of products and the latter places orders less often to purchase a low proportion of products. In the event of a flood, a manufacturing SME will inform its customers of the situation and that a reduced level of production will impact the degree to which orders placed can be met. During post-flood recovery, when production levels are lower than pre-flood, a manufacturing SME will rank customers such that priority customers are favoured over nonpriority customers. Such an approach is necessary to ensure, as far as possible, that priority customers' orders are met and thus customer satisfaction is maintained.

- Insurance companies: These businesses provide a manufacturing SME with basic or comprehensive insurance cover against damage to property and equipment, and/or disruption to business operations due to flooding. Furthermore, they may also assist a manufacturing SME's recovery by organizing and guaranteeing, at short notice, the attendance of electrical and/or cleaning contractors at a time when demand for their services is high. However, such 
assistance is dependent on the level of cover that a manufacturing SME has arranged with an insurance company.

- Mutual aid partners: Businesses that can provide floor space, including machinery and equipment, in which a flood affected manufacturing SME can temporarily locate some of its employees in order to continue the manufacture of its products during the period of disruption. Establishing a mutual aid agreement can be organized pre-flood or attempted to be set up during or post-flood. Agreements organized before a flood event has occurred, or is even expected to occur, can be invoked immediately thus enabling a flood affected manufacturing SME to maintain a degree of continuity in the manufacture of products and thus deliveries to customers. On the other hand, attempts to set up agreements during or post-flood may be time-consuming or delayed, even unsuccessful.

- Neighbouring businesses: Businesses in close proximity to a manufacturing SME that may exchange information about a flood event before it occurs and/or offer assistance pre and post-flood, e.g. a neighbouring business unaffected by the flood may be able to share floor space to store a manufacturing SME's equipment, products and/or raw materials.

- Suppliers: Under normal circumstances, manufacturing SMEs place orders with these businesses at varying frequency. However, after a flood event has occurred, orders are placed depending on an SME's varying manufacturing capacity in the recovery period and the level of orders from customers who will have been informed of the situation.

\subsection{Manufacturing SME agents}

\subsubsection{Attributes}

While the focus in this research is on modeling SMEs from the manufacturing sector, attributes of agents representing this type of business have been categorized as generic or specific. The former refers to those attributes independent of business sector whereas the latter relates to those particular to manufacturing SMEs. Table 4 provides a list and brief description of the generic attributes of a manufacturing SME. Generic attributes are further sub-categorized as being static or dynamic where the former remain unchanged throughout a simulation and the latter may vary in relation to the flood timeline. Some static, generic attributes are obtained from Ordnance Survey MasterMap's Address Layer*.

\begin{tabular}{|l|l|l|}
\hline Generic attribute & Brief description \\
\hline Static & Name $^{*}$ & The name of the SME business. \\
\cline { 2 - 3 } & NLUD code $^{*}$ & The National Land Use Database code. \\
\cline { 2 - 3 } & Coordinates of premises $^{*}$ & $\begin{array}{l}\text { The }(x, y) \text { coordinates of the SME's premises within } \\
\text { the Virtual Geographic Environment. }\end{array}$ \\
\hline
\end{tabular}




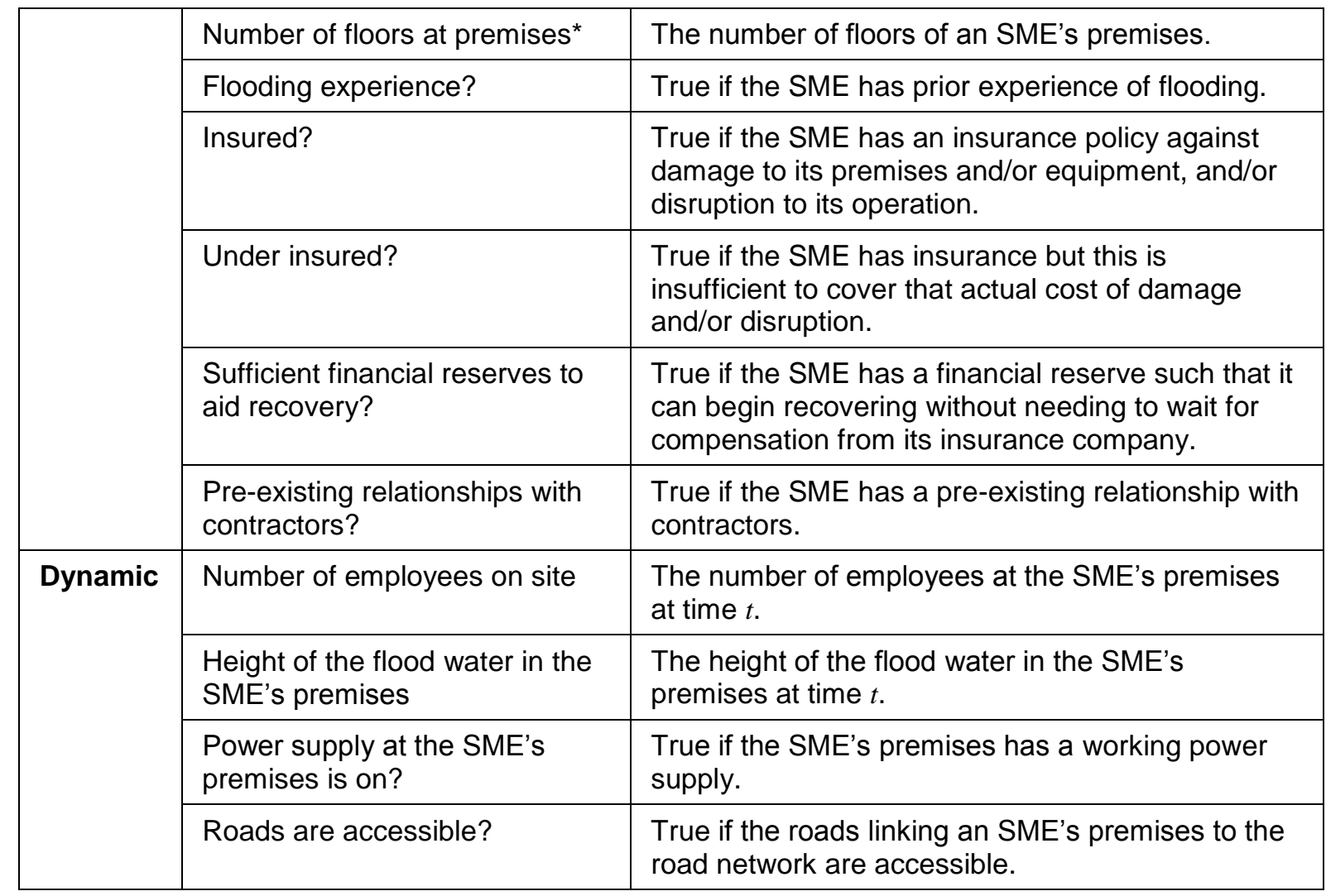

Table 4: Generic attributes of a manufacturing SME agent

Table 5 provides a list and brief description of the attributes of an SME specific to the manufacturing sector. All of these attributes are dynamic in nature as they may vary throughout a simulation.

\begin{tabular}{|l|l|}
\hline Sector-specific attribute & Brief description \\
\hline Raw materials stored at ground level & $\begin{array}{l}\text { The number of units of raw materials used to } \\
\text { manufacture products that are stored at ground level in } \\
\text { an SME's premises. }\end{array}$ \\
\hline $\begin{array}{l}\text { Raw materials stored above ground } \\
\text { level }\end{array}$ & $\begin{array}{l}\text { The number of units of raw materials used to } \\
\text { manufacture products that are stored above ground } \\
\text { level in an SME's premises. }\end{array}$ \\
\hline $\begin{array}{l}\text { Manufactured products stored at } \\
\text { ground level }\end{array}$ & $\begin{array}{l}\text { The number of manufactured products that are stored at } \\
\text { ground level in an SME's premises. }\end{array}$ \\
\hline $\begin{array}{l}\text { Manufactured products stored above } \\
\text { ground level }\end{array}$ & $\begin{array}{l}\text { The number of manufactured products that are stored } \\
\text { above ground level in an SME's premises. }\end{array}$ \\
\hline $\begin{array}{l}\text { Proportion of machines available to } \\
\text { manufacture products }\end{array}$ & $\begin{array}{l}\text { The proportion of machines used to manufacture } \\
\text { products that are available in an SME's premises given } \\
\text { that some may be damaged due to a flood event and } \\
\text { thus be in need of repair. }\end{array}$ \\
\hline Employees able to restore power? & $\begin{array}{l}\text { True if employees on site within an SME's workforce are } \\
\text { suitably skilled to carry out tasks related to the } \\
\text { restoration of power to the premises. }\end{array}$ \\
\hline
\end{tabular}

Table 5: Sector-specific attributes of a manufacturing SME agent 


\subsubsection{Behaviours: pre-flood response and post-flood recovery}

Behaviours exhibited by SMEs vary according to business sector. Also, it is recognised that SMEs from the same business sector can act differently in responding to and recovering from a flood event. Decisions regarding what behaviours that manufacturing SMEs should enact are based on information received from related businesses and organizations, e.g. flood alerts/warnings from the Environment Agency, and/or sensing its environment such as the presence and depth of flood water in or near its premises.

In this research, behaviours typical of a manufacturing SME have been categorized as those able to be enacted pre-flood and post-flood. While the majority of behaviours would be undertaken post-event by a flood affected manufacturing SME as it recovers, some could be enacted pre-event if a flood alert/warning was received, trusted and acted on. Pre-flood behaviours include responding in a way to reduce damage caused by water entering the premises. In contrast, post-flood behaviours focus on recovery from the inundation event to speed-up the resumption of manufacturing operations and return to pre-flood production levels. As stated earlier, semi-structured interviews with SMEs have provided the basis for the behaviours to be modeled, which are interrelated. Table 6 lists the pre and post-flood behaviours of a manufacturing SME modeled in this research.

\begin{tabular}{|l|l|}
\hline Flood stage & Behaviour of a manufacturing SME \\
\hline Pre-flood & Cover air-bricks \\
\cline { 2 - 3 } & Divert telephone landlines to mobile phones \\
\cline { 2 - 3 } & Evacuate \\
\cline { 2 - 3 } & Lift-up IT equipment \\
\cline { 2 - 3 } & Lift-up paper documents \\
\cline { 2 - 3 } & Lift-up products (if possible) \\
\cline { 2 - 3 } & Lift-up raw materials \\
\cline { 2 - 3 } & Normal production operation \\
\cline { 2 - 3 } & Seal doors with sandbags (if available) \\
\hline \multirow{5}{*}{ Post-flood } & Catalogue damage caused by flood water (for insurance purposes) \\
\cline { 2 - 3 } & Check power supply and electrical sockets \\
\cline { 2 - 3 } & Contact cleaning contractor \\
\cline { 2 - 3 } & Contact customers \\
\cline { 2 - 3 } & Contact electrical contractor \\
\cline { 2 - 3 } & Contact insurance company \\
\cline { 2 - 3 } & Contact IT specialist \\
\cline { 2 - 3 } & Contact suppliers \\
\cline { 2 - 3 } & Employees clean-up storage areas \\
\cline { 2 - 3 } & Employees clean-up the premises \\
\cline { 2 - 3 } & Employees clean-up the raw materials (that are salvageable) \\
\hline
\end{tabular}




\begin{tabular}{|l|l|}
\hline & Hire an electricity generator (if possible) \\
\cline { 2 - 3 } & Obtain cleaning tools and equipment \\
\cline { 2 - 3 } & Obtain funding (attempted if the SME is not cash-rich) \\
\cline { 2 - 3 } & Refurbish the premises \\
\cline { 2 - 3 } & Repair equipment and machines (once they have had sufficient time to dry) \\
\cline { 2 - 3 } & Restore IT system (including return to normal location and set-up) \\
\cline { 2 - 3 } & Restore power supply \\
\cline { 2 - 2 } & Set-up electricity generator (if hired) \\
\cline { 2 - 3 } & Supervise cleaning contractor (possible provided by insurer) \\
\cline { 2 - 3 } & Supervise electrical contractor \\
\cline { 2 - 3 } & Supervise IT specialist \\
\hline
\end{tabular}

Table 6: Pre and post-flood behaviours of a manufacturing SME

Pre-flood, under normal conditions, a manufacturing SME's employees would be occupied with production. In the event of a flood occurring without warning, employees would evacuate the premises. A manufacturing SME agent would recognise flood water had entered its premises by sensing the flood water depth in that location in the VGE was greater than zero at that time. However, if a flood alert/warning was received from the Environment Agency or a neighbouring business, then prior to evacuating some employees may take action to prevent items from being damaged or destroyed by the impending inundation. For example, employees may lift-up and move computers and other IT equipment, and even raw materials, to a height or location, if possible, where they would not be reached by the flood water. Figure 7 presents a flowchart indicating the pre-flood behaviours of a manufacturing SME that receives and acts on an Environment Agency flood alert/warning. 


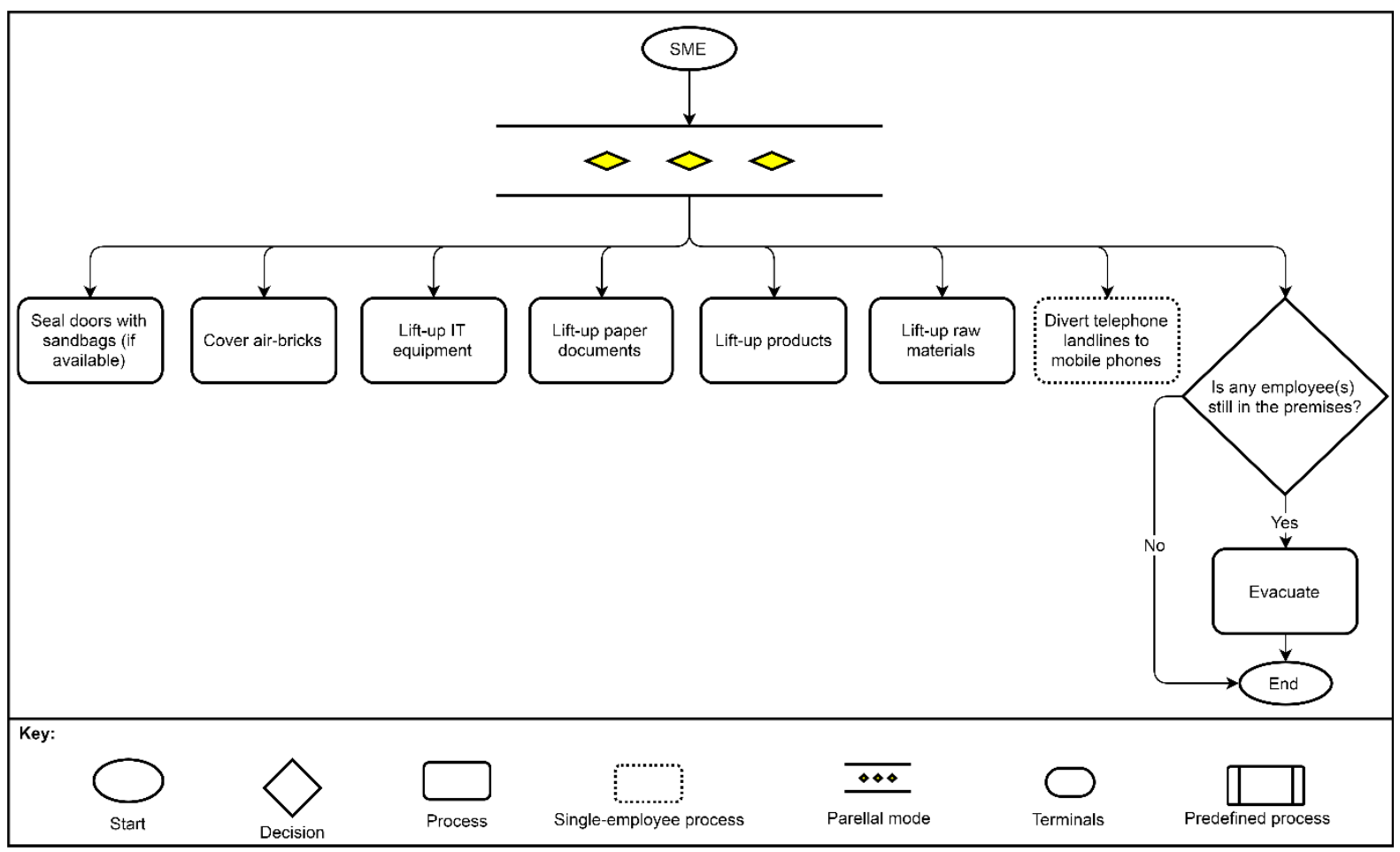

Figure 7: Pre-flood behaviours of a manufacturing SME that receives and acts on an Environment

Agency flood alert/warning

Post-flood, once employees have returned to work they would enact a series of behaviours in a logical order according to precedence relationships and priority. Furthermore, these behaviours, each of which has a duration range, may be able to be enacted by one employee or a number of employees. Typical behaviours include cataloguing the damage caused by the flood water and contacting the insurance company, which, depending on a manufacturing SME's level of cover, may organize service companies to attend the premises such as a contractor to perform electrical repairs and/or restore the power supply, and/or a contractor to carry out commercial cleaning. Alternatively, if a manufacturing SME has insufficient insurance cover and the electrics have been damaged and/or power supply has been interrupted, it may choose to contact directly an electrical contractor. In addition, it may need to obtain cleaning tools and equipment with which its own employees can clean raw materials, storage areas and the premises in general. Also, employees may be allocated to repairing equipment and machinery once they have had sufficient time to dry out. In the situation where a manufacturing SME does not have insurance, or adequate insurance, then it would need to source money if it did not have a financial reserve meaning sufficient funds were not immediately available. Figure 8 presents a flowchart indicating the potential interaction of a manufacturing SME, with an insurance company. In Figure 8, two predefined processes are included each of which has a corresponding flowchart. In relation to the insurance company contacting a cleaning contractor, the corresponding flowchart is presented as Figure $A 1$ in the Appendix. 


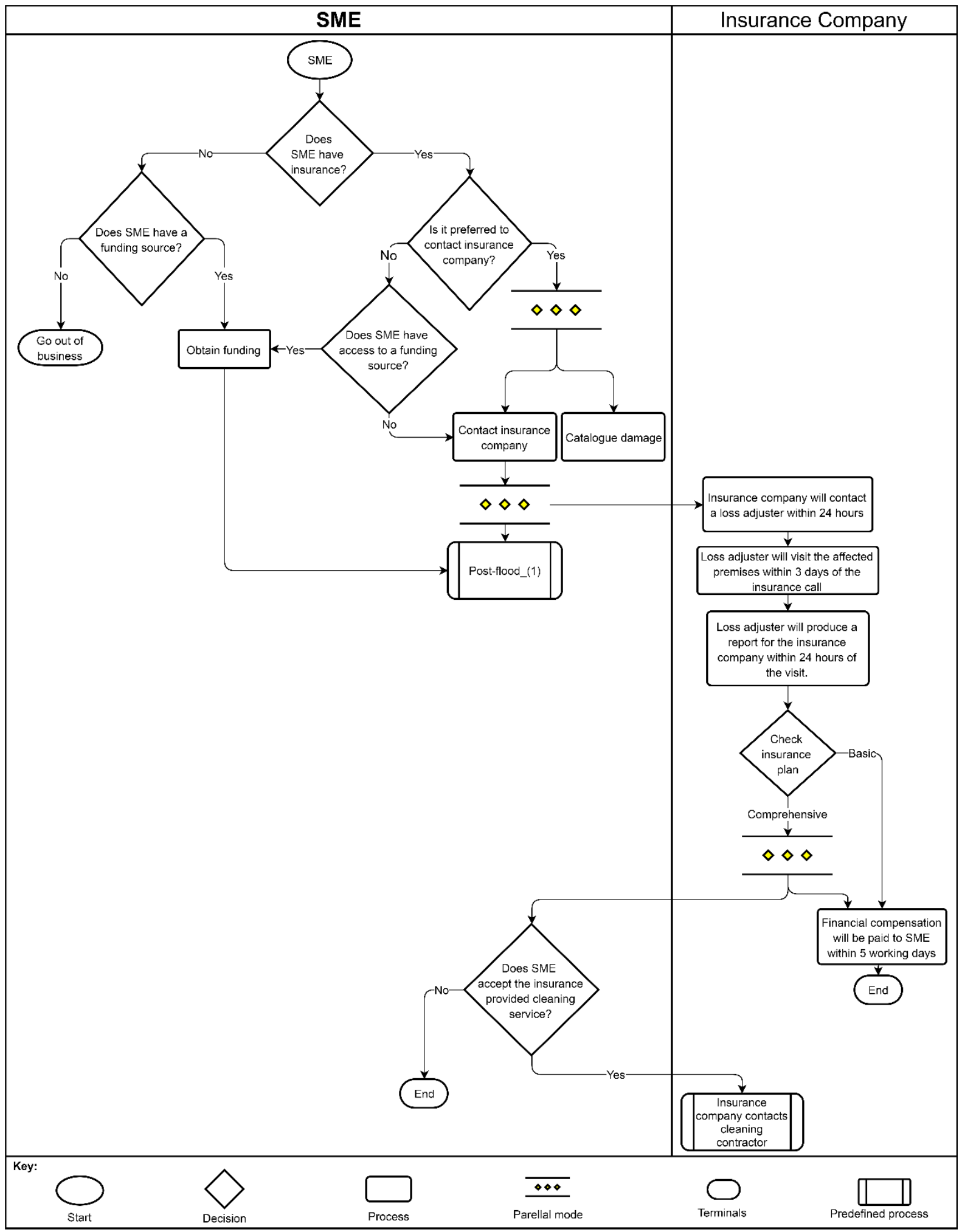

Figure 8: Manufacturing SME's post-flood behaviour related to insurance

Other post-flood behaviours include restoring the IT system, refurbishing the premises if necessary, and contacting customers to inform them of the potential impact of the flood event and communicating, when appropriate, with suppliers to order raw materials. Figure 9 presents the first of three flowcharts indicating a manufacturing SME's post-flood behaviours, which it may potentially 
enact. The two accompanying post-flood behaviour flowcharts are included as Figures A2 and A3 in the Appendix; Figure A3 refers to Figure A4 regarding an SME contacting customers and suppliers. In Figure 9, the pre-defined processes 'Contact insurance company' is that presented earlier in Figure 8 and 'Contact electrical contractor' is labelled Figure A5 in the Appendix. Note that Figure A5 relates to an SME's interaction with different types of contractor, not only electrical contractors.

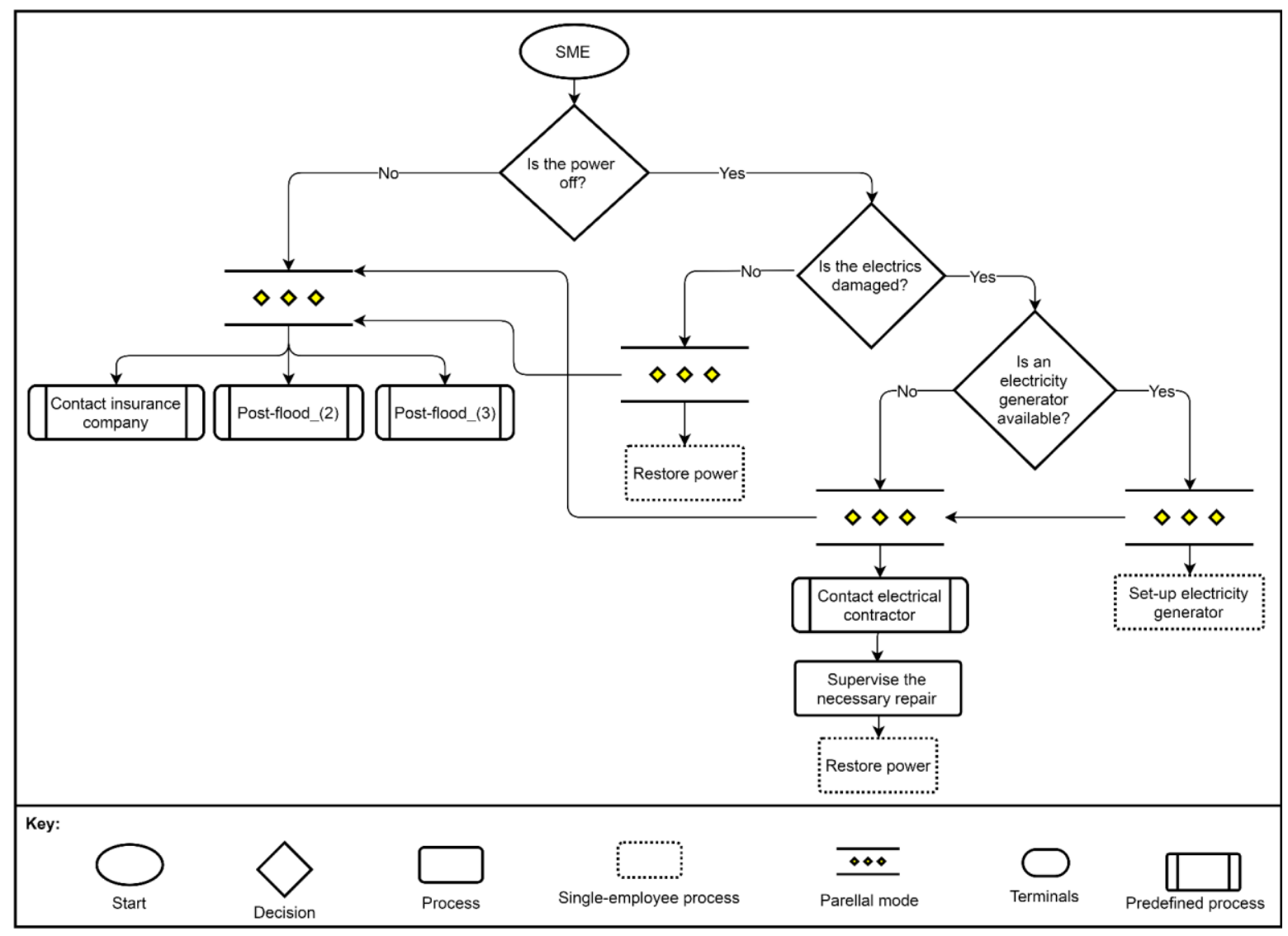

Figure 9: Post-flood behaviours of a manufacturing SME (1)

As the post-flood recovery behaviours are enacted over time, at some point a manufacturing SME will regain some level of production capacity and thus begin to resume making products. The rate at which production capacity is resumed can potentially be accelerated if an SME has implemented preparedness adaptation measures in advance of a flood event.

\subsubsection{Flood preparedness adaptation measures}

Based on interviews with 108 SMEs that have been flooded or are at risk of flooding, along with Environment Agency guidance and BCM literature, twenty five flood preparedness adaptation measures have been identified. These adaptation measures have been divided into two main categories, namely (1) physical/structural measures and (2) social measures. Furthermore, physical/structural adaptation measures to protect an SME's premises have been subdivided into those considered easy to implement or harder to implement. Similarly, social measures to aid and 
accelerate recovery have been subdivided into those viewed as being either internal or external. A complete list of the twenty five flood preparedness adaptation measures is given in Table 7 in Section 5.1 where simulation experiments are defined.

Physical/structural adaptation measures viewed as easy to implement include: keeping sandbags on site with which to seal doorways; protecting a premises by painting the exterior with waterproofing substances allied with deploying floodgates and airbrick covers; raising the level at which paper documents, raw materials and manufactured products are stored. Measures considered harder to implement include: installing flood resilient flooring, anti-back flow valves, a pump/sump system and electricity generator; building a bund wall; raising the level of machines, electrical sockets and consumer boards.

Internal social measures include: storing all documentation electronically and maintaining a backup of them; preparing a package of contacts (e.g. insurance company, customers, suppliers, contractors); preparing and maintaining an emergency plan for business continuity; performing emergency flood exercises; displaying flood plan instructions; setting up and maintaining an emergency financial reserve. Furthermore, external social measures include: registering for Environment Agency flood alerts/warnings; organizing insurance (basic or comprehensive); setting up pre-existing mutual aid agreements with other businesses (pre-flood) or identifying mutual aid partners (post-flood), and then invoking such an agreement.

All of the adaptation measures mentioned and others are included in Table 7 of Section 5.1. For each adaptation measure, implementation may not only affect the extent to which a manufacturing SME is impacted by a flood event, but also the behaviours enacted. More specifically, by implementing adaptation measures, a number of the typical behaviours may be undertaken pre-flood rather than post-flood, and the duration of one or more behaviours enacted post-flood in recovery may be reduced, or even removed from needing to be done.

In relation to physical/structural adaptation measures considered easy to implement, raising the level at which paper documents are stored such that they are not ruined by flood water could avoid delays in being able to contact a contractor at a time when the services of such businesses is in high demand. Also, if a proportion of raw materials in stock and/or products made were raised to be stored above ground level, then providing the flood water does not reach them, then they would not be damaged or destroyed. The use of sandbags would create a level of water resistance at doorways of a premises and thus provide a degree of protection up to a height of approximately $0.3 \mathrm{~m}$ or $0.5 \mathrm{~m}$ at best (Rickard, 2009). Thus, providing the flood water did not reach this level, and other measures were also in place, then none of the damage associated with water entering the premises via doorways would occur. Similarly, painting the building's exterior with waterproofing substances, and deploying floodgates and airbrick covers, would also provide the premises with a degree of water 
resistance thus potentially allowing production to continue as normal providing the employees can gain access to the premises.

For physical/structural adaptation measures considered harder to implement, raising the level of machines by building and locating them on elevated platforms may reduce the damage to them depending on the level that the flood water reaches if it enters a manufacturing SME's premises. Similarly, raising the position of electrical sockets and consumer boards may reduce the likelihood of them being damage and/or losing power to the premises should the flood water enter the building, which, in turn, means an SME would not need to request the services of an electrical contractor. A more extreme adaptation measure would be to build a bund wall surrounding an SME's premises providing it is detached. As long as the wall is not breached, this measure would negate the need for a number of behaviours such as lift-up and move IT equipment or for other protection measures to be implemented given that machines, raw materials and the premises would not be damaged by flood water. Consequently, production could continue as normal providing the employees could gain access to the premises each day. Other adaptation measures such as installing flood resilient flooring and anti-backflow valves may reduce the duration of enacting behaviours such as cleaning and refurbishing the premises.

With regard to internal social adaptation measures, storing all documentation electronically and maintaining a backup of them would avoid delays in contacting other businesses such as the insurance company, contractors, customers and suppliers. Backed up technical drawings may enable the technicians to repair machines more quickly thereby reducing down time. Preparing and maintaining an emergency flood plan for business continuity, performing emergency flood exercises and displaying emergency flood plan instructions may each, to varying degrees, reduce the duration of the vast majority of post-flood behaviours. Also, by setting up and maintaining an emergency financial reserve, then an SME would not need to source money post-flood thus allowing it to focus on enacting recovery behaviours.

External social adaptation measures include registering for Environment Agency flood alerts/warnings which would potentially allow an SME sufficient time to lift-up IT equipment before a flood event occurred. By arranging comprehensive insurance, an SME would be able to recover more quickly from a flood event than would otherwise be possible. For example, an SME with comprehensive insurance would quickly gain assistance, via its insurance company, from contractors rather than having to contact the service companies itself at what would be a competitive time to do so. Also, the arrangement of mutual aid agreements with other businesses may enable a flood affected manufacturing SME to maintain some level of production capacity during the period of disruption at its own premises. A manufacturing SME with pre-existing mutual aid partners would speed up the start of this off site production. In contrast, those without such an arrangement would first need to identify a potential partner or partners then attempt to organize an agreement, which may not even be possible or, at best, take more time than if an agreement had already been in place. 


\subsubsection{Performance metric}

Prior to defining the set of agent-based simulation experiments to be carried out to assess the effect of different combinations of adaptation measures on the recovery of manufacturing SMEs from a flood event, it is necessary to define the performance metric used to measure recovery. In all simulation experiments, for all manufacturing SMEs, loss in production capacity, $P C_{l o s s}$, due to the flood event was the performance metric used to provide an indication of the effectiveness of the different flood adaptation measures implemented. That is, adaptation measures that lead to a lower $P C_{\text {loss }}$ are more effective than those resulting in a greater $P C_{\text {loss }}$. Determining this performance metric is enabled by first calculating production capacity, $P C_{t}$, at each simulation time step or tick, $t$, which represents a 30 minute period in an agent-based simulation. More specifically, at each tick throughout a simulation, providing the SME's premises has power, $P C_{t}$ is calculated as a function of resources available, i.e. raw materials, machines and employees. Clearly, at a particular tick, if a manufacturing SME's premises does not have power, then production capacity is zero, i.e. $P C_{t}=0$.

At each simulation tick, if there is a power supply to a manufacturing SME's premises, $P_{t}=1$, and there is sufficient raw materials, $R M_{t}$, available, production capacity, expressed as a percentage, is determined according to equation (1),

$$
P C_{t}=\min \left(E_{t}, M_{t}\right) \times 100
$$

where $E_{t}$ is the ratio of available employees to the total number of employees, and $M_{t}$ is the ratio of available machines to the total number of machines. In relation to the term 'sufficient' raw materials, it is noted that at each simulation tick, one unit of raw material is consumed given (i) at least this amount is available, $R M_{t} \geq 1$, (ii) all employees are available and utilised, $E_{t}=1$, and (iii) all machines are available and utilised, $M_{t}=1$. Thus, for example, at a particular simulation tick, if $P_{t}=1, R M_{t} \geq 1, E_{t}=1$ and $M_{t}=1$, then in the associated 30 minute period a single unit of raw material is consumed and, consequently, $P C_{t}=100 \%$. However, still with $P_{t}=1$ and $R M_{t} \geq 1$, if not all employees and/or machines are available, i.e. $E_{t}<1$ and/or $M_{t}<1$, then only a fraction of a unit of raw materials will be consumed in production meaning $P C_{t}<100 \%$, calculated using equation (1), during the associated 30 minute period. Also, if no raw materials or employees or machines are available at a particular simulation tick, then $P C_{t}=0$. 
Still with power to the premises at a particular simulation tick, $P_{t}=1$, in the case of raw materials available at that tick being greater than zero but less than one, i.e. $0<R M_{t}<1$, if $R M_{t}<\min \left(E_{t}, M_{t}\right)$ then production capacity, expressed as a percentage, is determined according to equation (2),

$$
P C_{t}=R M_{t} \times 100
$$

However, for the same case mentioned, if $R M_{t} \geq \min \left(E_{t}, M_{t}\right)$, then equation (1) would be used to determine production capacity.

For each flood affected manufacturing SME, values of production capacity calculated at each tick throughout an agent-based simulation can be represented graphically as illustrated in Figure 10. Such a graph, or profile, of production capacity for a flood affected manufacturing SME is similar to the visualisation of disaster resilience seen in other research (Zobel, 2010, 2011). It is acknowledged that the actual profile of a flood affected manufacturing SME will be similar to, rather than the same as, that illustrated in Figure 10; however this figure permits a general explanation to be given as to how $P C_{\text {loss }}$ can be determined from such a representation.

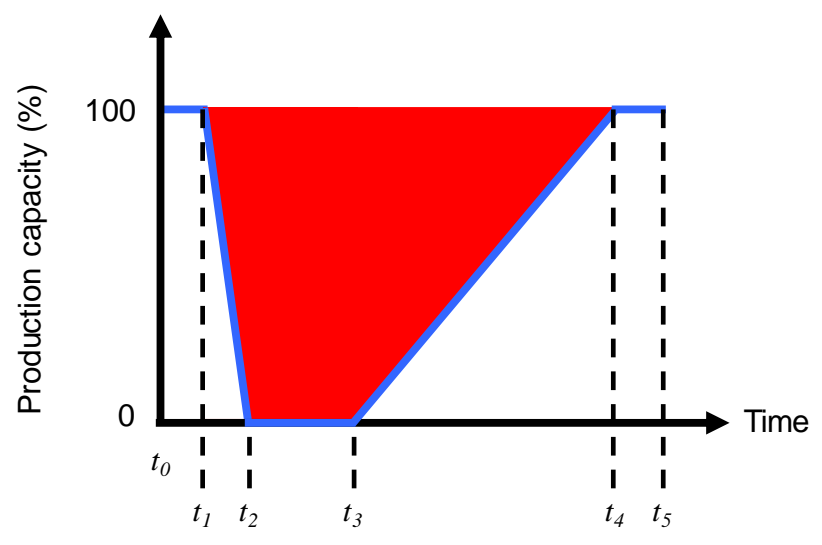

Figure 10: Production capacity of a manufacturing SME affected by a flood event versus time

In Figure 10, for a manufacturing SME affected by a flood event, production capacity, $P C$, represented by the blue line, varies throughout the time period simulated, i.e. from $t_{0}$ to $t_{5}$. Pre-flood, starting at $t_{0}$, normal production takes place such that $P C$ is maintained at $100 \%$. If at $t_{1}$ a manufacturing SME receives and acts on a flood alert/warning from the Environment Agency, then production may be reduced rapidly to zero before water enters its premises at $t_{2}$. This reduction in production between $t_{1}$ and $t_{2}$ is assumed to be linear given the short time over which it occurs relative to the period of an agent-based simulation. However, if a flood alert/warning is received but not acted on, or not received at all, then $t_{1}$ and $t_{2}$ would be coincident signifying that production halts immediately at the point the water enters a manufacturing SME's premises; thus in Figure 10 the blue line from $t_{1}$ 
to $t_{2}$ would be vertical rather than as shown. During the flood event and for a period of time post-flood, from $t_{2}$ to $t_{3}, P C$ remains at zero before beginning to increase at $t_{3}$. During the post-flood period, a flood affected manufacturing SME will enact recovery behaviours as described in Section 4.3.2. In Figure 10, for illustrative purposes, a linear increase in $P C$ is shown from $t_{3}$ to $t_{4}$ at which time $P C$ reaches $100 \%$. However, in reality, this increase would likely be non-linear given it is dependent on the recovery behaviours enacted by a manufacturing SME. Subsequently, from $t_{4} P C$ remains at $100 \%$ until $t_{5}$, which corresponds with the end of the agent-based simulation period. In contrast to the characterisation of a flood affected manufacturing SME shown in Figure 10, had the same business been unaffected by the flood event, $P C$ would remain at $100 \%$ throughout the period of time simulated.

In consideration of the illustration shown in Figure 10, the area coloured red is viewed as a manufacturing SME's loss in production capacity, $P C_{\text {loss }}$, as a result of a flood event. Thus, adaptation measures that are able to reduce this area, i.e. reduce the non-production period (from $t_{2}$ to $t_{3}$ ) and the recovery period (from $t_{3}$ to $t_{4}$ ) as well as increase the recovery rate (from $t_{3}$ to $t_{4}$ ), need to be investigated. In consideration of the illustration of a flood affected manufacturing SME, $P C_{\text {loss }}$ can be determined using equation (3),

$$
P C_{\text {loss }}=50\left(t_{4}+t_{3}-t_{2}-t_{1}\right)
$$

In relation to Figure 10 , as mentioned, the drop in production capacity between $t_{1}$ and $t_{2}$ is assumed to be linear given the short time over which this occurs relative to the entire agent-based simulation period. However, as referred to earlier, the recovery of production from $t_{3}$ to $t_{4}$ would likely not be linear; thus equation (3) must be modified to reflect this non-linearity as shown in equation (4),

$$
P C_{\text {loss }}=50\left(2 t_{4}-t_{2}-t_{1}\right)-\int_{t_{3}}^{t_{4}} f(t) d t
$$

where $f(t)$ is the polynomial of best fit of the recovery in production capacity from 0 to $100 \%$ in the period from $t_{3}$ to $t_{4}$, which can be established using statistical regression.

As a simple example, returning to equation (3) and Figure 10, with an agent-based simulation period from $t_{0}=0$ to $t_{5}=1200$, for a manufacturing SME, referred to as 'A', that received and acted on an alert/warning from the Environment Agency at $t_{1}=50$ and had its premises flooded at $t_{2}=60$, and with the subsequent period of non-production lasting until $t_{3}=200$ from which time production increased linearly until reaching $100 \%$ at $t_{4}=750$, then $P C_{\text {loss }}=42,000$ units. In contrast, considering the same simulation period for a different manufacturing SME, say 'B', experiencing the 
same flood, i.e. $t_{1}=50$ and $t_{2}=60$, but with some preparedness adaptation measures in place such that the business resumed production at $t_{3}=170$ and production capacity reached $100 \%$ at $t_{4}=550$, then $P C_{\text {loss }}=30,500$ units. To allow a more understandable and meaningful comparison between these values of $P C_{\text {loss }}$, it is useful to relate them to the production capacity of the manufacturing SME over the same time period of the agent-based simulation had the company been unaffected by the flood event, i.e. $100\left(t_{5}-t_{0}\right)$, such that,

$$
P C_{\text {loss }}^{A B S}=\frac{P C_{\text {loss }}}{100\left(t_{5}-t_{0}\right)}
$$

Thus, for the simple example discussed, over the time period of the agent-based simulation (from $t_{0}=0$ to $t_{5}=1200$ ), manufacturing SME 'A' and 'B' would have a production capacity loss of $P C_{\text {loss }}^{A B S}=35.0 \%$ and $P C_{\text {loss }}^{A B S}=25.4 \%$ respectively. Using the time frame defining the agent-based simulation period enables a fair comparison of production capacity loss not only for different SMEs, which are affected by the flood event at different times and to different extents, but also those implementing varying combinations of preparedness adaptation measures as will be seen in Section 5.

\subsection{Validation overview}

Prior to defining the agent-based simulation experiments performed and discussing the associated results in Section 5, an overview of the ABMS's validation is presented. In order to improve the credibility of the ABMS of manufacturing SMEs' response and recovery to flood events, along with its implementation, the simulation development process shown in Figure 11 (Heath et al., 2009) was used as a basis.

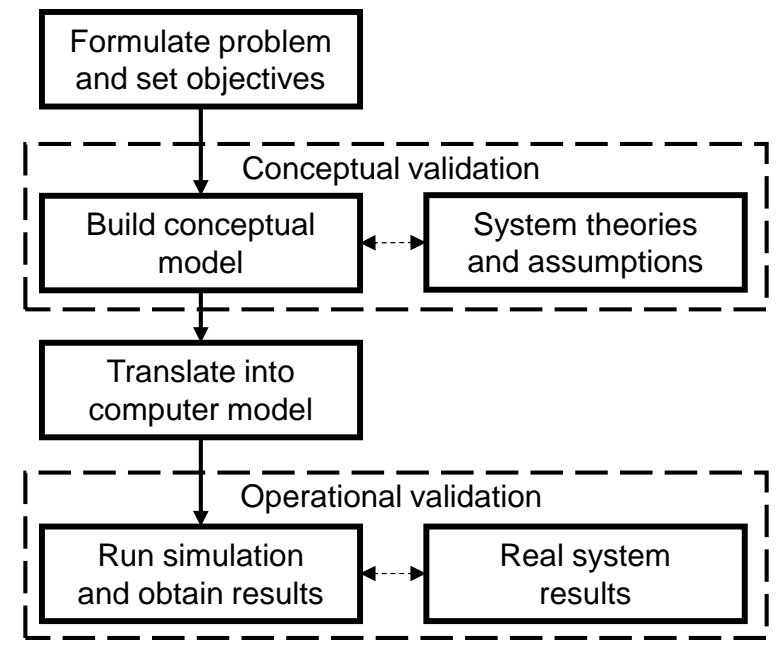


Figure 11: Simulation development process involving conceptual and operational validation (Heath et al., 2009)

While the process illustrated in Figure 11 provided the basis for the validation of the ABMS developed in this research, it is acknowledged that other methodologies exist for developing and validating 'agent-oriented' systems (Burstein \& Gregor, 1999; DeLoach, Wood, \& Sparkman, 2001; G. Fortino \& North, 2013; Giancarlo Fortino, Garro, \& Russo, 2005; Giancarlo Fortino \& Russo, 2012; Klügl, 2008; Niazi, 2011; Salamon, 2011).

In this research, the simulation development process used involves conceptual validation of the abstract model of the real system and operational validation of its implementation as an agent-based simulation. More specifically, the simulation development process shown in Figure 12 was adapted from the process shown in Figure 11 in order to enable assessments of manufacturing SMEs' response to flood events in silico by using agents. Importantly, for both conceptual and operation validation, SMEs' owners, managers and employees were consulted.

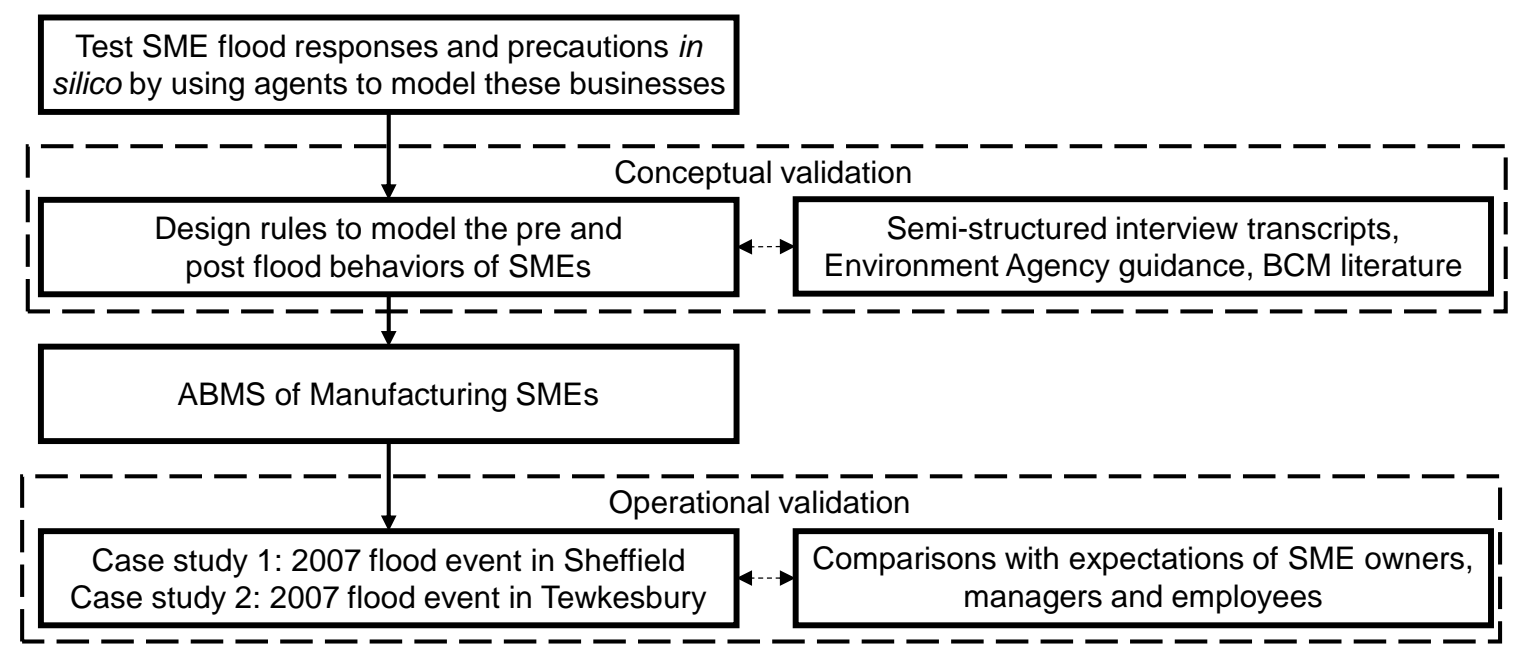

Figure 12: The simulation development process used in this paper

\subsubsection{Conceptual validation}

Initially a conceptual model was developed based on information gleaned from a number of sources. Primarily, ABM development focused on manufacturing SME agents based on information extracted from semi-structured interviews with businesses at risk of flooding and/or that had experienced flooding. In total, 108 semi-structured interviews were undertaken, many of which were from the manufacturing business sector. However, initial conceptual model development involved the analysis of only 73 semi-structured interviews. The remaining 35 interviews were carried out after a workshop was held to enable face-to-face validation with SME owners, managers and employees as discussed later in this section. These initial 73 interview transcripts revealed how SMEs that had been flooded in 
the past behaved before, during and after the flood, what the impact was on business operations, and what, if any, plans for business continuity and resilience had been put in place for future floods. Similarly, SMEs faced with the risk of flooding indicated how they would expect to behave if a flood event occurred and what they have done to protect their premises and reduce potential disruption to operations. This extensive source of practical information contributed significantly to establishing the rules governing manufacturing SME agents' pre- and post-flood behaviours in terms of responding to and recovering from a flood event respectively. In addition, the interviews provided information in terms of interactions between SMEs and related businesses / organizations that needed to be modeled. Other sources used to inform ABM development included Environment Agency guidance, business continuity management literature and academic literature related to flood risk management. All of these sources contributed to the further development of rules governing agent behaviour and interactions between different types of agents.

Once agent models had been developed, incorporating the design rules to model pre and post-flood behaviours of SMEs, a workshop attended by owners, managers and employees from such small businesses was held in Sheffield. At this workshop, conceptual validation involved presenting and explaining the agent models developed to the aforementioned personnel from a variety of SMEs. In addition, owners, managers and employees were asked a range of questions: (a) Are all of the types of businesses and organizations represented? (b) Are all of the links between businesses and organizations present? (c) Are there any behaviours missing, or included but should be removed, for manufacturing SMEs? (d) Are there any interaction behaviours missing, or included but should be removed, between manufacturing SMEs and other businesses and organizations? (e) Are the events or conditions causing transitions between behaviours accurate? (f) Are there any transitions between behaviours that could occur which have not been included? These questions revealed a number of important issues and omissions related to the agent models. For example, the interactions between a manufacturing SME and an insurance company, and the ensuing involvement of other organisations such as contractors that would attend to aid cleaning-up an SME's premises, was not fully understood. Relatedly, the way in which an SME may choose to allocate its own employees to enact behaviours depending on factors such as flood severity and insurance level required further consideration. These examples, and others, highlighted the need for specific input from more SMEs at risk of flooding and/or with experience of flooding. Thus, as referred to earlier, interviews were held with an additional 35 SMEs leading to further agent model development. In addition, meetings took place with insurance brokers and workshops were held for the Insurance Institute of Middlesbrough and Newcastle, which provided useful information in the process of conceptual validation.

\subsubsection{Operational validation}

After the conceptual model had undergone validation as summarised in Section 4.4.1, it was then implemented as part of the ABMS component of the modeling and simulation framework overviewed in Section 2. As part of the ABMS implementation process, operational validation was performed by 
comparing simulation output for two case studies against SMEs' expectations. The two case studies used for operational validation were the 2007 flood event in both Sheffield, South Yorkshire and Tewkesbury, Gloucestershire.

In relation to operational validation, the ultimate aim, via improvements being made to the ABMS, was to be able to confirm with SME personnel that the simulated businesses' responses to and recoveries from the modeled flood events presented were acceptable representations of that which would be expected in reality. In order to facilitate operational validation, two workshops were held; the first in Tewkesbury and then the second approximately one week later in Sheffield. Holding the workshops in these two locations was seen as important given that the flood events were modeled in these areas and, very importantly, some of the SMEs in attendance had experience of the actual 2007 flood events. As with conceptual validation, these workshops involved presenting and explaining agent models, and simulation output, to SME owners, managers and employees. This process of operational validation led to a series of improvements being suggested by SME personnel. Also, in separating the workshops by one week, an opportunity was taken after the first meeting to make changes to the ABMS, and as a consequence generate more credible simulation output, prior to the second meeting taking place. In this process, the main improvements identified were related to the preferred order in which behaviours may be undertaken by SMEs and the permissible time range of particular behaviours.

\section{Agent-based simulation results}

Agent-based simulations have been performed to investigate the effect of different preparedness adaptation measures that manufacturing SMEs may implement to lessen the impact of flooding and accelerate recovery, thus strengthening their organizational resilience. As discussed in Section 3, comparable to the severe flooding experienced in 2007, a one in 1000 year flood event in the Lower Don Valley region of Sheffield in the UK has been modeled and simulated, which based on Ordnance Survey MasterMap's Address Layer data would affect 100 of the region's manufacturing SMEs. As indicated in Table 1 of Section 1, given the predominance of micro sized SMEs (95.6\% of 99.9\%), the results discussed in this paper focus on this size of business and with each having nine employees. Moreover, given the relatively small number of employees in a micro sized business, it is assumed that all of them can contribute to the main function of a manufacturing SME which is the manufacture of products, i.e. production.

\subsection{Experiments}

Twenty five preparedness adaptation measures have been identified based on 108 interviews with SMEs in the UK that have been flooded or are at risk of flooding, as well as Environment Agency guidance and BCM literature. As discussed in Section 4.3.3, these adaptation measures have been categorized as physical/structural measures that are easy to implement or harder to implement, and 
social measures that are internal or external to a manufacturing SME. Combinations of these adaptation measures to be assessed using agent-based simulation, defined as experiments, are presented in Table 7. Each of the twenty five adaptation measures under consideration can be in one of two states, i.e. true or false indicating that a measure has been implemented or not implemented respectively. For the purpose of the investigation reported in this paper, as shown in Table 7, sixteen experiments were defined where a ticked cell signifies 'true' or the adaptation measure 'has been implemented' and an empty cell indicates 'false' or 'has not been implemented'. 


\begin{tabular}{|c|c|c|c|c|c|c|c|c|c|c|c|c|c|c|c|c|c|}
\hline \multirow{2}{*}{\multicolumn{2}{|c|}{ Flood preparedness adaptation measures }} & \multicolumn{16}{|c|}{ Experiment (E) } \\
\hline & & 1 & 2 & 3.1 & 3.2 & 3.3 & 3.4 & 4 & 5 & 6 & 7 & 8 & 9 & 10 & 11 & 12 & 13 \\
\hline \multicolumn{18}{|c|}{ Physical/Structural (easy to implement) } \\
\hline PE1 & Have emergency mobiles and operate a telephone diverting call service & & & $\checkmark$ & $\checkmark$ & $\checkmark$ & $\checkmark$ & $\checkmark$ & $\checkmark$ & $\checkmark$ & & & $\checkmark$ & & & $\checkmark$ & \\
\hline PE2 & Raise the level of paper documents & & & $\checkmark$ & $\checkmark$ & $\checkmark$ & $\checkmark$ & & & & & & $\checkmark$ & & $\checkmark$ & $\checkmark$ & \\
\hline PE3 & Raise the level of raw materials & & & $\checkmark$ & & & $\checkmark$ & & & & & & $\checkmark$ & & $\checkmark$ & $\checkmark$ & \\
\hline PE4 & Raise the level of products & & & $\checkmark$ & $\checkmark$ & $\checkmark$ & $\checkmark$ & & & & & & $\checkmark$ & & $\checkmark$ & $\checkmark$ & \\
\hline PE5 & Keep sandbags on site to seal doorways & & $\checkmark$ & $\checkmark$ & $\checkmark$ & $\checkmark$ & $\checkmark$ & $\checkmark$ & $\checkmark$ & $\checkmark$ & & & $\checkmark$ & & $\checkmark$ & $\checkmark$ & \\
\hline PE6 & Paint exterior of building with waterproofing substances, deploy floodgates and airbrick covers & & $\checkmark$ & & $\checkmark$ & & $\checkmark$ & & & & & & $\checkmark$ & & $\checkmark$ & $\checkmark$ & \\
\hline \multicolumn{18}{|c|}{ Physical/Structural (harder to implement) } \\
\hline $\mathrm{PH} 1$ & Has an electricity generator & & & $\checkmark$ & $\checkmark$ & $\checkmark$ & $\checkmark$ & & & & & & $\checkmark$ & & & & $\checkmark$ \\
\hline $\mathrm{PH} 2$ & Raise the level of machines & & & $\checkmark$ & $\checkmark$ & $\checkmark$ & $\checkmark$ & & & & & & $\checkmark$ & & $\checkmark$ & & $\checkmark$ \\
\hline $\mathrm{PH} 3$ & Raise electrical sockets and consumer boards & & & $\checkmark$ & $\checkmark$ & $\checkmark$ & $\checkmark$ & & & & & & $\checkmark$ & & & & $\checkmark$ \\
\hline $\mathrm{PH} 4$ & Move raw materials to a safer location & & & & $\checkmark$ & $\checkmark$ & & & & & & & & & & & $\checkmark$ \\
\hline $\mathrm{PH} 5$ & Build a bund wall & & & $\checkmark$ & & $\checkmark$ & & & & & & & & & & & $\checkmark$ \\
\hline $\mathrm{PH} 6$ & Install flood-resilient flooring & & & $\checkmark$ & $\checkmark$ & $\checkmark$ & $\checkmark$ & & & & & & $\checkmark$ & & & & $\checkmark$ \\
\hline $\mathrm{PH} 7$ & Install anti-backflow valves & & & $\checkmark$ & $\checkmark$ & $\checkmark$ & $\checkmark$ & & & & & & $\checkmark$ & & & & $\checkmark$ \\
\hline $\mathrm{PH} 8$ & Install and use pump/sump system & & & $\checkmark$ & $\checkmark$ & $\checkmark$ & $\checkmark$ & & & & & & $\checkmark$ & & & & $\checkmark$ \\
\hline \multicolumn{18}{|c|}{ Social (internal) } \\
\hline $\mathrm{SI} 1$ & Store all documentation electronically and maintain backups of them & & & & & & & $\checkmark$ & $\checkmark$ & & $\checkmark$ & & $\checkmark$ & & & & \\
\hline $\mathrm{SI} 2$ & Prepare a package of contacts (e.g. customers, suppliers, insurance company, contactors) & & & & & & & $\checkmark$ & $\checkmark$ & & $\checkmark$ & & $\checkmark$ & & & & \\
\hline $\mathrm{SI3}$ & Prepare and maintain an emergency plan for business continuity & & & & & & & $\checkmark$ & $\checkmark$ & & $\checkmark$ & & $\checkmark$ & & & & \\
\hline $\mathrm{SI} 4$ & Perform emergency flood exercises & & & & & & & $\checkmark$ & $\checkmark$ & & $\checkmark$ & & $\checkmark$ & & & & \\
\hline SI5 & Display flood plan instructions & & & & & & & $\checkmark$ & $\checkmark$ & & $\checkmark$ & & $\checkmark$ & & & & \\
\hline SI6 & Set up and maintain an emergency financial reserve & & & & & & & $\checkmark$ & $\checkmark$ & & $\checkmark$ & & $\checkmark$ & & & & \\
\hline \multicolumn{18}{|c|}{ Social (external) } \\
\hline SE1 & Register for Environment Agency flood alerts and warnings & & & & & & & $\checkmark$ & & $\checkmark$ & & $\checkmark$ & $\checkmark$ & $\checkmark$ & & & \\
\hline SE2 & Has comprehensive insurance cover & & & & & & & $\checkmark$ & $\checkmark$ & $\checkmark$ & $\checkmark$ & $\checkmark$ & $\checkmark$ & & & & \\
\hline SE3 & Has pre-existing mutual aid partner(s) & & & & & & & $\checkmark$ & & $\checkmark$ & & $\checkmark$ & $\checkmark$ & & & & \\
\hline SE4 & Identify mutual aid partner(s) & & & & & & & $\checkmark$ & & $\checkmark$ & & $\checkmark$ & $\checkmark$ & & & & \\
\hline SE5 & Request mutual aid & & & & & & & $\checkmark$ & & $\checkmark$ & & $\checkmark$ & $\checkmark$ & & & & \\
\hline
\end{tabular}

Table 7: Definition of experiments involving manufacturing SME flood preparedness adaptation measures 
The adaptation measures listed In Table 7 are referred to as being related to preparedness, and thus would be implemented before a flood event occurred or was expected to occur. However, it is acknowledged that SE4, 'identify mutual aid partner(s)', may be undertaken during or post-flood by a manufacturing SME that had not done so prior to the event. In addition, in terms of insurance cover, it is assumed that all manufacturing SMEs have at least basic cover, unless indicated as has comprehensive insurance cover' in SE2, which relates to the level of assistance provided by an insurance company, including organizing help from contractors, in the event of a business being flooded.

Experiment E1 acts as a datum, or benchmark, in which none of the twenty five preparedness adaptation measures were implemented by manufacturing SMEs. Experiment E2 has SMEs with only two of the most common easy to implement physical/structural measures aimed at preventing flood water entering the business's premises, namely keeping sandbags on site which can be used to seal doorways in the event of a flood (PE5), and painting the building's exterior with waterproofing sealants, deploying floodgates and airbrick covers (PE6). Experiments E3.1 to E3.4 focus on various combinations of physical/structural measures, both easy and harder to implement. Experiment E4 includes all internal and external social measures implemented whereas E5 and E6 focus mainly on internal and external social measures respectively. Also, in E4, E5 and E6, two easy to implement physical/structural measures are included (PE1, PE5). Experiment E7 is similar to E5, as E8 is similar to E6, but without the two easy to implement physical/structural measures. Experiment E9 includes the vast majority of all physical/structural and social measures implemented. Note that E9 does not include all measures, specifically not the harder to implement physical/structural adaptation measures of moving raw materials to a safe location (PH4) and building a bund wall (PH5). The rationale for not including these in this experiment is that the effective alternative easy to implement physical/structural adaptation measures of raising the level of raw materials (PE3) and paint exterior of building with waterproofing substances, deploy floodgates and airbrick covers (PE6) have been modeled as being in place. Experiment E10 has manufacturing SMEs with the sole external social measure of registering for Environment Agency flood alerts/warnings (SE1). Experiment E11 involves the majority of easy to implement physical/structural measures and a single harder to implement physical/structural measure (PH2). Finally, Experiment E12 involves all easy to implement physical/structural measures whereas experiment E13 includes all physical/structural measures that are considered harder to implement.

In the sixteen experiments defined in Table 7, several other parameters were also considered: (i) the number of electrical and cleaning contractors available in the geographical area was set to be equal to the number of flood affected manufacturing SMEs; (ii) the number of flood affected manufacturing SMEs with a pre-existing relationship with contractors was set at zero; (iii) in the first three days postflood, $80 \%$ of employees returned to work; (iv) all manufacturing SMEs were modeled as not having experience of flooding. Additional experiments with different settings for these parameters are discussed in Section 5.2 . 
Based on 20 repeats of agent-based simulations for each experiment E1 to E13, involving all 100 flood affected manufacturing SMEs modeled as being micro sized and having nine employees, production capacity each simulation tick was calculated as explained in Section 4.3.4. For a selection of these experiments, graphs of average production capacity are shown in Figure 13. It is noted that since the graphs presented are based on the average production capacity of all 100 manufacturing SMEs, they do not correspond explicitly to a particular company.

For all experiments, the agent-based simulation period started at 7.30 a.m. on day 1 (tick 0 ) and ended at tick 1647 corresponding to an approximate duration of 33.3 days within which the 45 hour flood modeled and simulated occurred. Due to each of the 100 flood affected manufacturing SMEs being located in different geographical locations within Sheffield's Lower Don Valley, the precise time at which flood water reached a particular company's premises varied but only by several ticks. However, the approximate start and end times of the flood were 12.00 p.m. on day 2 (tick 58) and 4.30 a.m. on day 4 (tick 139) respectively. Furthermore, in all simulations, a working day was modeled as having 10 hours starting at 8.00 a.m. and finishing at 6.00 p.m.

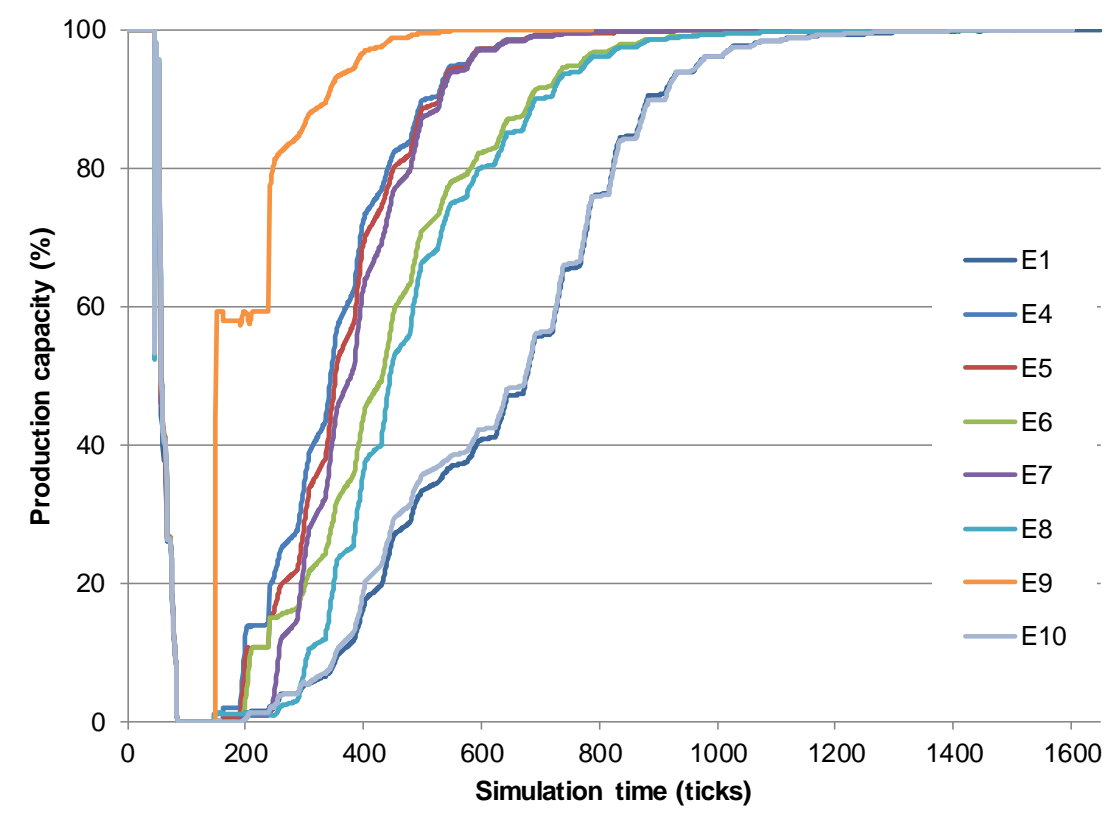

Figure 13: Average production capacity of 100 flood affected manufacturing SMEs versus time

In contrast with the simple illustration of a production capacity graph shown in Figure 10, which includes a linear recovery period (from $t_{3}$ to $t_{4}$ ), it can be seen in Figure 13 that the recovery periods obtained via agent-based simulation are non-linear. Thus, statistical regression was used to establish a polynomial of best fit for the recovery period part of each production capacity graph. The general polynomial regression model, or $n$th degree polynomial in one variable, is stated in equation (6) where 
the expected value of the dependent variable, $f(t)$, is expressed in terms of the independent variable or regressor, $t$, the unknown parameters or regression coefficients, $\beta_{i}$, and a random error term, $\varepsilon$.

$$
f(t)=\beta_{0}+\beta_{1} t+\beta_{2} t^{2}+\beta_{3} t^{3}+\cdots+\beta_{n} t^{n}+\varepsilon
$$

For example, for the datum experiment E1 shown in Figure 13, the polynomial best fitting the data in the recovery period (defined as being from $t_{3}$ to $t_{4}$ in relation to Figure 10), with $R^{2}=0.9945$, was

$$
f(t)=2.95-\left(6.31 \times 10^{-2}\right) t+\left(5.83 \times 10^{-4}\right) t^{2}-\left(6.05 \times 10^{-7}\right) t^{3}+\left(1.82 \times 10^{-10}\right) t^{4}
$$

Based on the statistical regression analyses carried out on the production capacity graph associated with each experiment, equation (4) was used to determine average $P C_{\text {loss }}$ and equation (5) for average $P C_{\text {loss }}^{A B S}$ of all flood affected manufacturing SMEs as indicated in Table 8. It is noted that for the graph related to experiment E9, which corresponds with all manufacturing SMEs being modeled as having the vast majority of physical/structural and social adaptation measures implemented, equation (4) was modified to account for the near immediate resumption of production capacity, to approximately $60 \%$, post-flood.

\begin{tabular}{|c|c|c|}
\hline Experiment & Average $P C_{\text {loss }}$ (units) & Average $P C_{\text {loss }}^{A B S}$ (\%) \\
\hline 1 & 57,618 & 35.0 \\
\hline 2 & 25,875 & 15.7 \\
\hline 3.1 & 24,097 & 14.6 \\
\hline 3.2 & 18,853 & 11.5 \\
\hline 3.3 & 24,367 & 14.8 \\
\hline 3.4 & 18,799 & 11.4 \\
\hline 4 & 28,879 & 17.5 \\
\hline 5 & 30,198 & 18.3 \\
\hline 6 & 38,102 & 23.1 \\
\hline 7 & 32,217 & 19.6 \\
\hline 8 & 41,628 & 25.3 \\
\hline 9 & 14,239 & 8.6 \\
\hline 10 & 57,007 & 34.6 \\
\hline 11 & 25,381 & 15.4 \\
\hline 12 & 25,593 & 15.5 \\
\hline 13 & 25,638 & 15.6 \\
\hline
\end{tabular}

Table 8: Average $P C_{\text {loss }}$ and $P C_{\text {loss }}^{A B S}$ due to the flood event modeled for experiments $\mathrm{E} 1$ to $\mathrm{E} 13$

For the experiments undertaken, Figure 14 shows a visual representation of the values of average $P C_{\text {loss }}^{A B S}$ indicated in Table 8. 


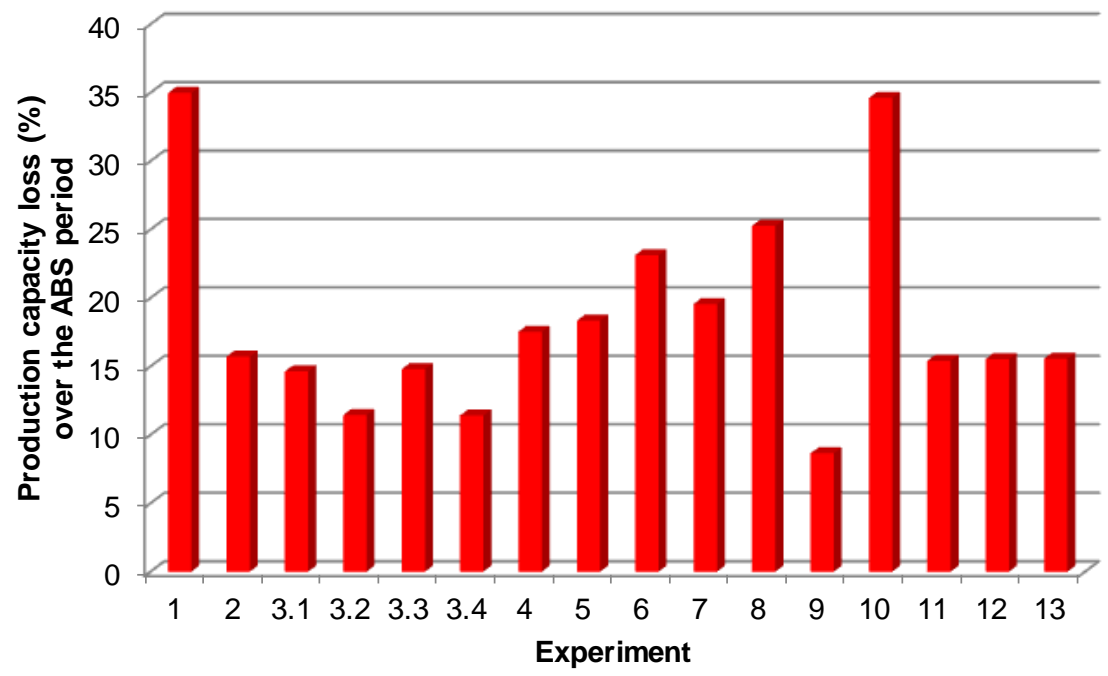

Figure 14: $P C_{\text {loss }}^{A B S}$ due to the flood event modeled for experiments $\mathrm{E} 1$ to $\mathrm{E} 13$

As indicated in Figure 14, as a result of the one in 1000 year event considered, flood affected manufacturing SMEs without any adaptation measures implemented (E1) yields the greatest average $P C_{\text {loss }}^{A B S}$ of $35.0 \%$. In contrast, the lowest average $P C_{\text {loss }}^{A B S}$ is $8.6 \%$ which corresponds with manufacturing SMEs having implemented almost all physical/structural and social measures (E9) to protect their premises from water inundation and the associated damage, and minimise disruption to production operations. Identifying E1 and E9 as the two extreme experiments could have been predicted prior to performing any agent-based simulations. However, predicting the relative effectiveness of other combinations of flood preparedness adaptation measures is not intuitive; this is where the value of agent-based simulation may be greatest by allowing manufacturing SMEs to assess the effect of different adaptation measures and combinations of them.

Comparing experiment E2 with E1, the results obtained suggest that manufacturing SMEs with two of the most common easy to implement physical/structural measures (PE5, PE6) reduces average $P C_{\text {loss }}^{A B S}$ by almost $20 \%$ from $35.0 \%$ to $15.7 \%$. Such a significant reduction demonstrates the effectiveness of using sandbags allied with waterproofing the exterior of the building, and deploying floodgates and airbrick covers, to prevent flood water entering a business's premises. However, it is recognised that the protection offered by such measures is dependent on the depth that the flood water reaches at a company's premises.

Experiments E3.1 and E3.3 suggest that putting in place the majority of easy and harder to implement physical/structural measures is marginally more effective than adaptation measure PE6, i.e. waterproofing the exterior of the building, deploying floodgates and airbrick covers as in E2. Specifically, experiments E3.1 and E3.3 have an average $P C_{\text {loss }}^{A B S}$ of $14.6 \%$ and $14.8 \%$ respectively, 
which is approximately only $1 \%$ better (lower) than for E2. This suggests that preventing flood water from penetrating an SME's premises in the first instance, as in E2, offers effective protection as well as removing the need for many of the other physical/structural measures, both easy and harder to implement. However, had the flood water breached the waterproofing then the benefits of the other physical/structural measures would come into effect. Experiments E3.2 and E3.4 which, in addition to various easy and harder to implement physical/structural measures, include waterproofing the building, deploying floodgates and airbrick covers, result in a $P C_{\text {loss }}^{A B S}$ of $11.5 \%$ and $11.4 \%$ respectively, which is approximately $3 \%$ less than in E3.1 and E3.3. This difference in $P C_{\text {loss }}^{A B S}$ again demonstrates the effectiveness of adaptation measure PE6. A further point recognised in experiments E3.1 to E3.4 relates to a comparison between waterproofing a manufacturing SME's premises versus building a bund wall around it. In the research presented in this paper, the construction of a bund wall to protect premises from flooding was identified as being done by only one of over 100 businesses interviewed. This uncommon and expensive physical/structural adaptation measure, viewed as being harder to implement, does offer a degree of protection in that it can prevent flood water, below a certain depth, from entering a premises. However, the height of a bund wall built for this purpose is relatively low when compared with that at which waterproofing sealant can be applied to a building's exterior. Thus, waterproofing a building can be more effective than building a bund wall.

As expected, experiments E4, E5 and E6 demonstrate the finding that implementing both internal and external social measures $\left(E 4\right.$, average $\left.P C_{l o s s}^{A B S}=17.5 \%\right)$ is more effective than implementing only internal social measures (E5, average $P C_{l o s s}^{A B S}=18.3 \%$ ) or only external social measures (E6, average $P C_{\text {loss }}^{A B S}=23.1 \%$ ). Further, the differences in average $P C_{\text {loss }}^{A B S}$ for these experiments indicate that internal social measures over which a manufacturing SME has more control, as opposed to external measures such as mutual aid that depend partially on the cooperation of other businesses, contributes more to the reduction in average $P C_{\text {loss }}^{A B S}$ achieved.

In relation to internal and external social measures, experiments E7 and E8 enable a similar comparison to be made as to that between E5 and E6 less the two easy to implement physical/structural measures (PE1, PE5). Experiments E7 and E8 result in an average $P C_{\text {loss }}^{A B S}$ of $19.6 \%$ and $25.3 \%$ respectively, suggesting, as did E5 and E6, that internal social measures are more effective than external measures. Moreover, the difference in $P C_{l o s s}^{A B S}$ of $5.7 \%$ between experiments E7 and E8 is comparable to that between E5 and E6, i.e. $4.8 \%$, thus providing confidence in the reliability of the results comparing internal versus external social adaptation measures. A comparison of experiments $\mathrm{E} 7$ and $\mathrm{E} 5$, with average $P C_{\text {loss }}^{A B S}$ of $19.6 \%$ and $18.3 \%$ respectively, suggests the inclusion of the two easy to implement physical/structural measures involving using sandbags, along with emergency mobiles and a telephone diverting call service, results in approximately a $1 \%$ 
improvement. A similar finding is revealed when comparing experiments E8 and E6, with average $P C_{l o s s}^{A B S}$ of $25.3 \%$ and $23.1 \%$ respectively; however, the difference in this case is approximately $2 \%$.

Experiment E10, with manufacturing SMEs only implementing the measure of registering for Environment Agency alerts/warnings gives an average $P C_{\text {loss }}^{A B S}$ of $34.6 \%$, which is marginally $(0.4 \%)$ better than that achieved in the datum experiment E1. The relatively minor difference between these experiments implies that, while warnings are useful, the associated limited time they allow to enact pre-flood response behaviours does not have a significant influence on a manufacturing SME's recovery post-flood. As such, registering for Environment Agency alerts/warnings would need to be implemented in conjunction with other adaptation measures.

Experiments E11, E12 and E13, enabling a comparison to be made between manufacturing SMEs with easy to implement and harder to implement physical/structural measures, all yield similar average $P C_{\text {loss }}^{A B S}$, i.e. $15.4 \%, 15.5 \%$ and $15.6 \%$ respectively. A comparison between experiments $\mathrm{E} 13$ and E3.3 (with a $P C_{\text {loss }}^{A B S}$ of $14.8 \%$ ), shows that despite the latter also including four of the easy to implement physical/structural measures (PE1, PE2, PE4, PE5), the difference in average $P C_{\text {loss }}^{A B S}$ is approximately only $1 \%$. As recognised for experiments E3.1 to E3.4, this marginal difference can be attributed to the four easy to implement physical/structural measures not including waterproofing the premises, along with deploying floodgates and air brick covers, which is effective in preventing flood water from penetrating a building.

In summary, experiments E1 to E13 have enabled an assessment to be made of the effectiveness of different combinations of adaptation measures that manufacturing SMEs may implement to lessen the impact of flooding, accelerate recovery and quicken the return to pre-flood production levels. Agentbased simulation results suggest that easy to implement physical/structural measures are equally as effective as those considered harder to implement. This is supported by experiments E12 and E13 which resulted in a $P C_{\text {loss }}^{A B S}$ of $15.5 \%$ and $15.6 \%$ respectively. However, it is noted that waterproofing the exterior of a building, along with deploying floodgates and air brick covers, is the most effective measure in preventing flood water from penetrating a company's premises, thus removing the need to enact many post-flood recovery behaviours. Physical/structural measures have also been shown to be more effective than both internal and external social measures; experiments E7 and E8 yielded a $P C_{\text {loss }}^{A B S}$ of $19.6 \%$ and $25.3 \%$ respectively. Additionally, these results suggest internal social measures are more effective than external ones.

As indicated in Section 5.1, in experiments E1 to E13, (i) the number of electrical and cleaning contractors available was set equal to the number of flood affected manufacturing SMEs, (ii) the number of flood affected manufacturing SMEs having a pre-existing relationship with contractors was 
set at zero, (iii) in the first three days post-flood, $80 \%$ of employees were assumed to have returned to work in each manufacturing SME, and (iv) all manufacturing SMES were modeled as not having experience of flooding. In consideration of experiment E9, which resulted in the lowest $P C_{\text {loss }}^{A B S}(8.6 \%)$ of all the initial experiments undertaken, variations in these four parameters was studied to assess their influence on a manufacturing SME's recovery from the flood event modeled and simulated. The number of contractors, both electrical and cleaning contractors, available in the geographical area was set to meet (a) $100 \%$ or (b) $75 \%$ of the demand of flood affected manufacturing SMEs, meaning that in (a) all of these businesses would receive assistance when requested, whereas in (b) this would not necessarily happen immediately and may be significantly delayed. Related to this parameter, the number of flood affected SMEs with a pre-existing relationship with contractors was set at (a) zero or (b) $50 \%$. Businesses with a pre-existing relationship would receive preferential treatment from contractors as this would speed up attendance. However, those without such a relationship would need to attempt to contact contractors at a time when demand for them is high which may mean a delay in attendance, or if already in attendance the service being interrupted due to a request from a flood affected SME with a pre-existing relationship. The remaining parameters considered were the proportion of employees returning to work post-flood in the first three days after the flood event (i.e. $20 \%, 50 \%$ and $80 \%$ ) and whether or not an SME had experience of flooding, both of which would have an impact on the duration of recovery behaviours needing to be enacted post-flood. For experiment E9, Table 9 summarises the additional experiments undertaken based on the four parameters discussed, where a ticked cell signifies 'true' and an empty cell indicates 'false'. In Table 9, experiment A corresponds with the initial experiment E9. 


\begin{tabular}{|c|c|c|c|c|c|c|c|c|c|c|c|}
\hline \multirow[t]{2}{*}{ Parameters } & \multicolumn{11}{|c|}{ Experiment } \\
\hline & A & $\mathrm{B}$ & $\mathrm{C}$ & $\mathrm{D}$ & $\mathrm{E}$ & $\mathrm{F}$ & $\mathrm{G}$ & $\mathrm{H}$ & 1 & $J$ & $\mathrm{~K}$ \\
\hline \multicolumn{12}{|l|}{ Number of electrical contractors } \\
\hline Able to meet $75 \%$ of demand of flood affected manufacturing SMEs & & & & & & & $\checkmark$ & $\checkmark$ & $\checkmark$ & $\checkmark$ & $\checkmark$ \\
\hline Able to meet $100 \%$ of demand of flood affected manufacturing SMEs & $\checkmark$ & $\checkmark$ & $\checkmark$ & $\checkmark$ & $\checkmark$ & $\checkmark$ & & & & & \\
\hline \multicolumn{12}{|l|}{ Number of cleaning contractors } \\
\hline Able to meet $75 \%$ of demand of flood affected manufacturing SMEs & & & & & & & $\checkmark$ & $\checkmark$ & $\checkmark$ & $\checkmark$ & $\checkmark$ \\
\hline Able to meet $100 \%$ of demand of flood affected manufacturing SMEs & $\checkmark$ & $\checkmark$ & $\checkmark$ & $\checkmark$ & $\checkmark$ & $\checkmark$ & & & & & \\
\hline \multicolumn{12}{|c|}{ Proportion of flood affected manufacturing SMEs with pre-existing relationships with contractors } \\
\hline $0 \%$ & $\checkmark$ & $\checkmark$ & $\checkmark$ & $\checkmark$ & $\checkmark$ & $\checkmark$ & $\checkmark$ & & & & \\
\hline $50 \%$ & & & & & & & & $\checkmark$ & $\checkmark$ & $\checkmark$ & $\checkmark$ \\
\hline \multicolumn{12}{|l|}{ Proportion of employees returning to work in first three days post flood } \\
\hline $80 \%$ & $\checkmark$ & & & $\checkmark$ & & & $\checkmark$ & $\checkmark$ & $\checkmark$ & & \\
\hline $50 \%$ & & $\checkmark$ & & & $\checkmark$ & & & & & $\checkmark$ & \\
\hline $20 \%$ & & & $\checkmark$ & & & $\checkmark$ & & & & & $\checkmark$ \\
\hline \multicolumn{12}{|l|}{ Flood experience } \\
\hline Flood affected manufacturing SME has flood experience & & & & $\checkmark$ & $\checkmark$ & $\checkmark$ & & & $\checkmark$ & $\checkmark$ & $\checkmark$ \\
\hline
\end{tabular}

Table 9: Additional experiments performed in relation to initial experiment E9 
As for the initial experiments undertaken, based on 20 repeats of agent-based simulations for each additional experiment $\mathrm{B}$ to $\mathrm{K}$, involving all 100 flood affected manufacturing SMEs being modeled as having nine employees, the average value of production capacity was calculated at each tick throughout the simulation period. Subsequently, based on statistical regression analyses carried out on the production capacity graph of each additional experiment simulated, in consideration of all 100 flood affected manufacturing SMEs, equation (4) was used to determine average $P C_{\text {loss }}$ and equation (5) for average $P C_{\text {loss }}^{A B S}$ which is presented in Figure 15.

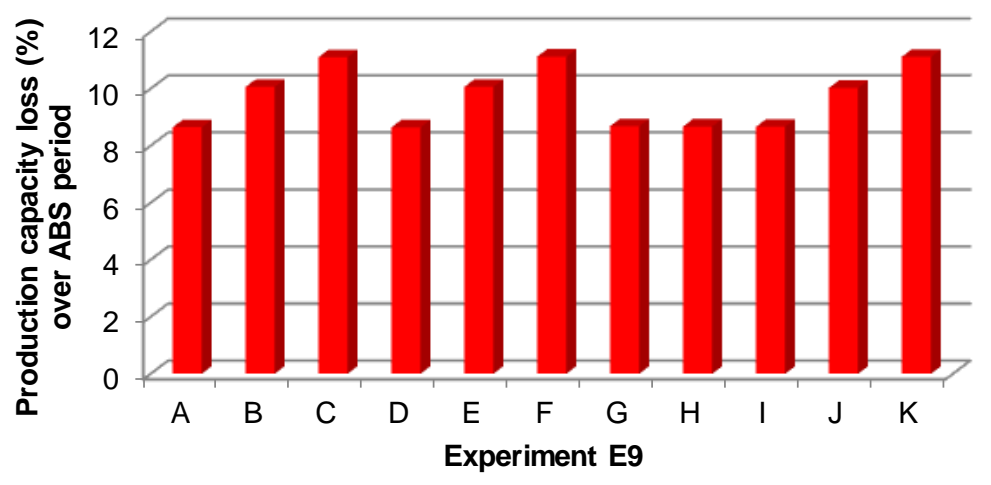

Figure 15: $P C_{\text {loss }}^{A B S}$ due to the flood event modeled for experiments $\mathrm{A}$ to $\mathrm{K}$

As indicated earlier, experiment $\mathrm{A}$ corresponds with the initial experiment $\mathrm{E} 9$ with $P C_{\text {loss }}$ of $8.6 \%$.

Experiments $\mathrm{A}, \mathrm{B}$, and $\mathrm{C}$ enable a comparison to be made of the effect on $P C_{\text {loss }}^{A B S}$ of the proportion of employees returning to work in the first three days post-flood. As expected, $P C_{l o s s}^{A B S}$ increases as this proportion is reduced. That is, in the first three days post-flood, employee return rates of $80 \%$, $50 \%$ and $20 \%$ led to $P C_{\text {loss }}^{A B S}$ of $8.6 \%, 10.1 \%$ and $11.1 \%$ respectively. Thus, for micro-sized manufacturing SMEs, with only nine employees, return rate post-flood is important in aiding recovery. Experiments $D, E$, and $F$ are similar to $A, B$, and $C$ but include all manufacturing SMEs having flood experience. Despite this difference, experiments $\mathrm{D}, \mathrm{E}$, and $\mathrm{F}$ return almost identical values of $P C_{\text {loss }}^{A B S}$ as $A, B$, and $C$ respectively. Thus, for manufacturing SMEs with the vast majority of physical/structural and social measures implemented, having flood experience has no discernible effect. That is, having almost all adaptation measures in place removes the need to enact most of the post-flood recovery behaviours. As a consequence, this negates the potential benefits that having experience of flooding would bring had they not been implemented. Such experience would likely become beneficial in the case of manufacturing SMEs without as many adaptation measures in place and so needing to enact post-flood recovery behaviours. 
Experiments $\mathrm{G}$ and $\mathrm{H}$ allow a comparison to be made between zero and $50 \%$ of manufacturing SMEs having pre-existing relationships with contractors. Both experiments produce the same $P C_{\text {loss }}^{A B S}$ of 8.7\% leading to the deduction that for manufacturing SMEs having almost all adaptation measures in place the demand for a contractor is removed. With flood experience discounted for manufacturing SMEs with almost all adaptation measures in place, experiments $\mathrm{H}$ and $\mathrm{I}$ are essentially equivalent.

This is supported in that both result in exactly the same $P C_{\text {loss }}^{A B S}$ of $8.7 \%$, thus providing confidence in the reliability of the results obtained.

In light of the finding that manufacturing SMEs with almost all adaptation measures in place negates the effect of both having flood experience and pre-existing relationships with contractors, experiments $\mathrm{I}, \mathrm{J}$, and $\mathrm{K}$ become comparable to $\mathrm{A}, \mathrm{B}$, and $\mathrm{C}$. That is, these experiments enable a comparison of the effect on $P C_{\text {loss }}^{A B S}$ of the proportion of employees returning to work in the first three days post-flood. For experiments $\mathrm{I}, \mathrm{J}$, and $\mathrm{K}, P C_{\text {loss }}^{A B S}$ is the same as that obtained for $\mathrm{A}, \mathrm{B}$, and $\mathrm{C}$ respectively, i.e. $8.6 \%, 10.1 \%$, and $11.1 \%$. This agreement in $P C_{\text {loss }}^{A B S}$ provides further confidence in the earlier observation that flood experience makes no difference in terms of accelerating recovery for manufacturing SMEs with almost all adaptation measures implemented.

\section{Conclusions}

Businesses can be severely affected by flooding if ill-prepared, especially SMEs which due to their predominance can result in significant economic losses to a nation's economy. Thus, there is a need to investigate the effectiveness of flood preparedness adaptation measures that SMEs can put in place to lessen the impact of a flood event in terms of damage and disruption, accelerate recovery and thus strengthen organizational resilience. The research presented in this paper focuses on the development and use of ABMS, coupled with flood modeling and simulation, enabling what-if style experiments to be performed to assess how manufacturing SMEs fare in the event of a significant flood. Each experiment performed corresponds with the implementation of various combinations of physical/structural and social adaptation measures.

In order to more realistically model SMEs' response to and recovery from a flood event than would have been otherwise possible, over 100 interview transcripts with this type of business have been analysed. Access to these transcripts led to manufacturing SME agents being modeled to behave in their virtual environment as closely as possible to how they would do so in reality faced with the same circumstances. In addition to modeling manufacturing SMEs, the ABM includes agents representing related businesses and organizations, with which interactions can play an important role in an SME's recovery. In conjunction with ABMS, a one in 1000 year flood event in the Lower Don Valley region of Sheffield in the UK is modeled and simulated. This location is selected due to having a high concentration of SMEs, many of which experienced significant flooding in June 2007. Agent-based 
simulation experiments involving different combinations of preparedness adaptation measures facilitated the evaluation of manufacturing SMEs' performance using the metric of loss in production capacity due to a flood event. Based on an analysis of these simulation results, a series of insights are offered in relation to the impact of the configuration of preparedness measures on the performance metric being assessed. Moreover, the simulations performed have led to findings that may inform manufacturing SMEs how to better adapt to flood risk. Specifically, results suggest that physical/structural measures are more effective than internal social measures which, in turn, are more effective than external social measures. Physical/structural measures considered easy to implement are equally as effective as those viewed as harder to implement. However, results suggest that applying water resistant substances to the exterior of an SME's premises, along with deploying floodgates and air brick covers, is the most effective adaptation measure in preventing flood water penetrating a business's property. Indeed, by stopping water entering a manufacturing SME's premises, this measure removes the need to enact many of the post-flood recovery behaviours that would otherwise be necessary. However, in the event of flood water breaching waterproofing and entering an SME's premises, the benefits of employing other adaptation measures come into effect. Importantly, it is recognised that the flood preparedness adaptation measures considered each have an associated financial cost, which a manufacturing SME would need to take into account when determining whether or not they should or could be implemented.

In terms of future work, agents will be developed to include the potential for variations in their interaction preferences. In addition, agents representing SMEs from business sectors other than manufacturing will be modeled. Relatedly, appropriate performance metrics will need to be defined for these SMEs. Also, while the research presented in this paper has focused on micro-sized SMEs, which account for the vast majority of SMEs, future work will include investigations of the behaviour of small sized and medium-sized businesses. Further, investigations will be carried out into how variations in the number of employees within each category of SME can affect a business's recovery. Intuitively, SMEs with more employees available to enact post-flood behaviours should lead to a reduction in the recovery period. However, within each of the three categories of SME, agent-based simulation experiments could be conducted to investigate what number of employees is sufficient to gain the greatest reduction in recovery time and expedite the resumption of production operations. In relation to simulations performed, in addition to the datum experiment, only fifteen experiments have been considered involving combinations of the twenty five flood preparedness adaptation measures identified. More combinatorial experiments could be defined and simulated enabling a greater insight into the effectiveness of different configurations of adaptation measures. Also, the additional experiments conducted to test the effect on SMEs' recovery from a flood event of different proportions of (a) contractors being available to assist SMEs, and (b) SMEs having pre-existing relationships with contractors influence SME recovery, could be extended. This would allow an assessment to me made of the influence of competition when these businesses do not have almost all physical/structural and social adaptation measures in place. 


\section{Acknowledgements}

The authors gratefully acknowledge the funding provided by the UK'S EPSRC under grant EP/K012770/1. Also, we thank colleagues from the universities of Sheffield, Kingston and the West of England who kindly provided the transcripts of interviews with SMEs. In accordance with a research agreement with Ordnance Survey regarding MasterMap's Address Layer, the associated data used in this research is not available. 


\section{Appendix}

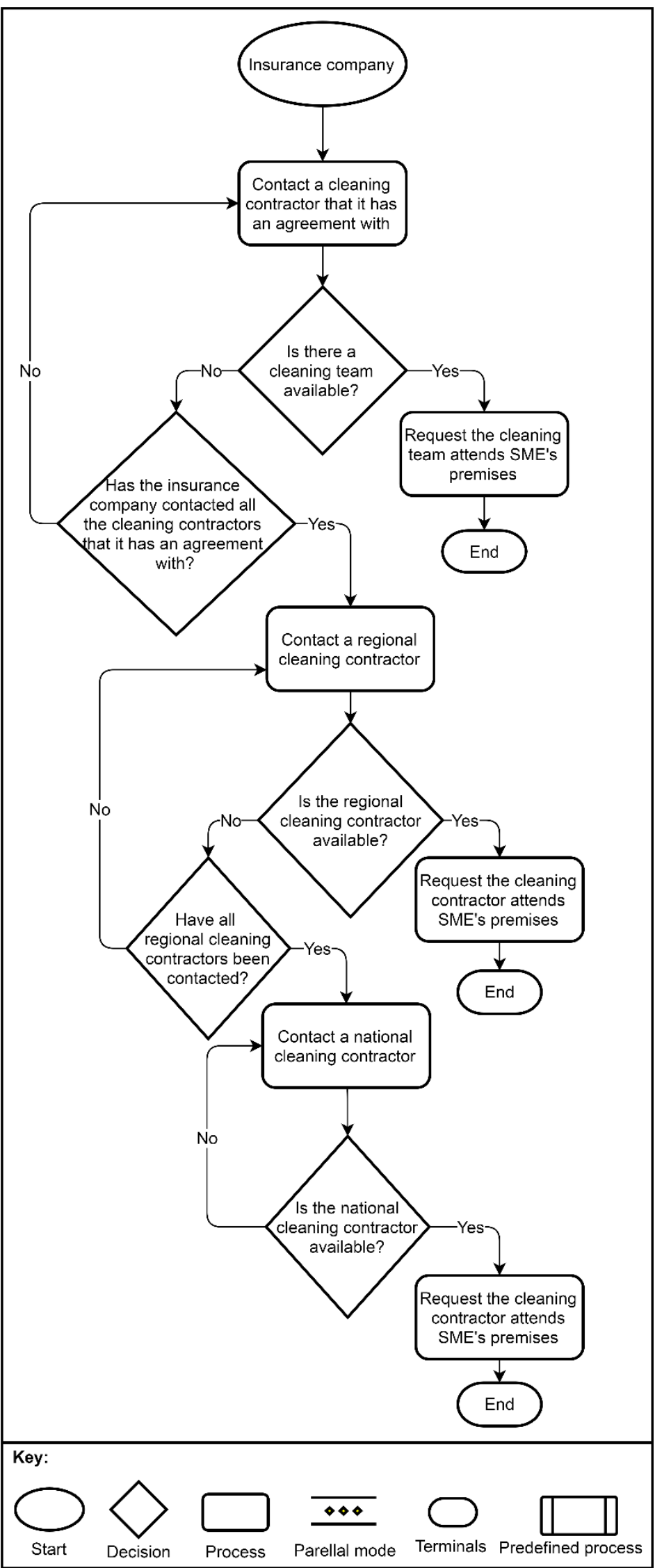

Figure A1: Insurance company interaction with a cleaning contractor 


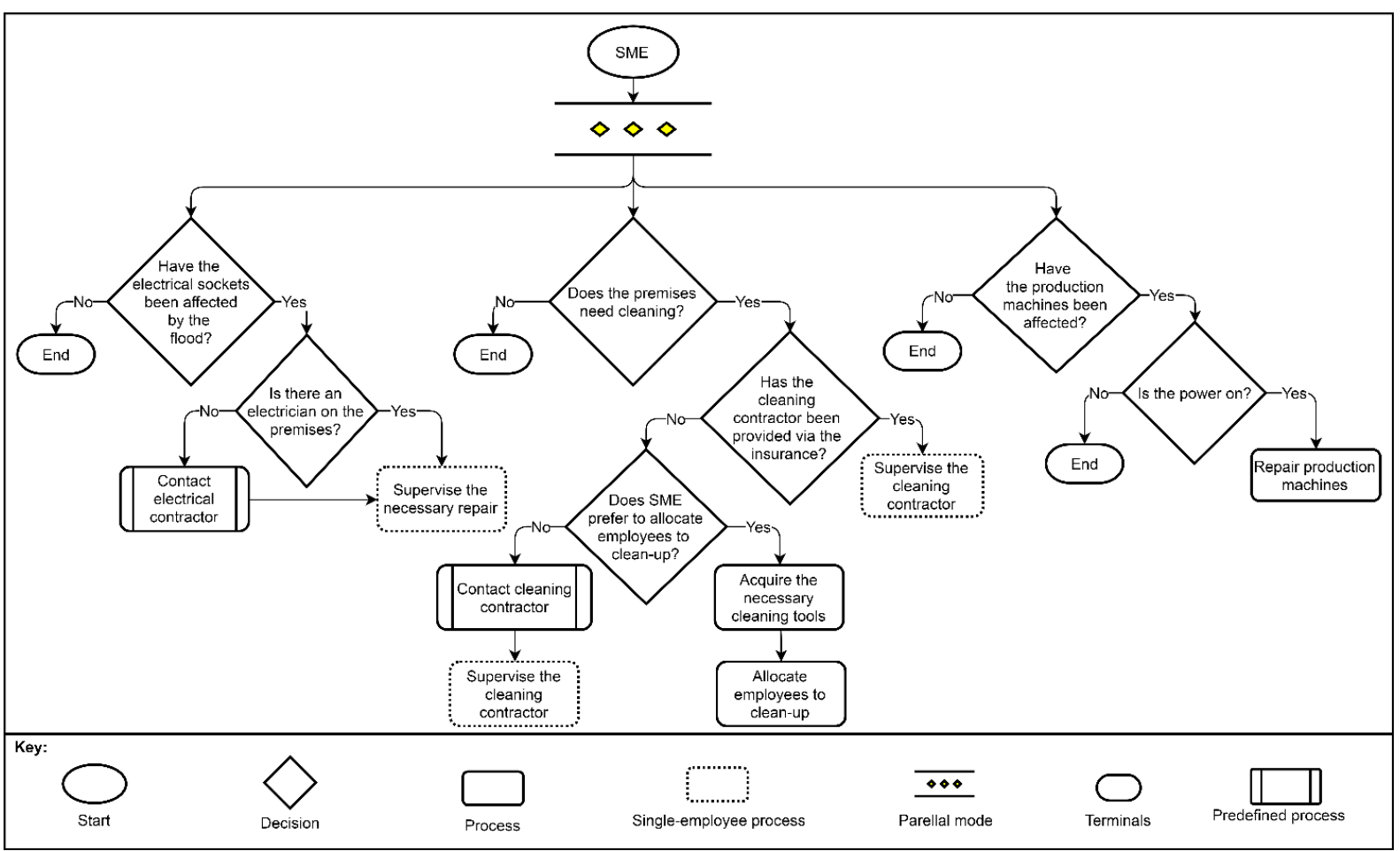

Figure A2: Post-flood behaviours of a manufacturing SME (2) 


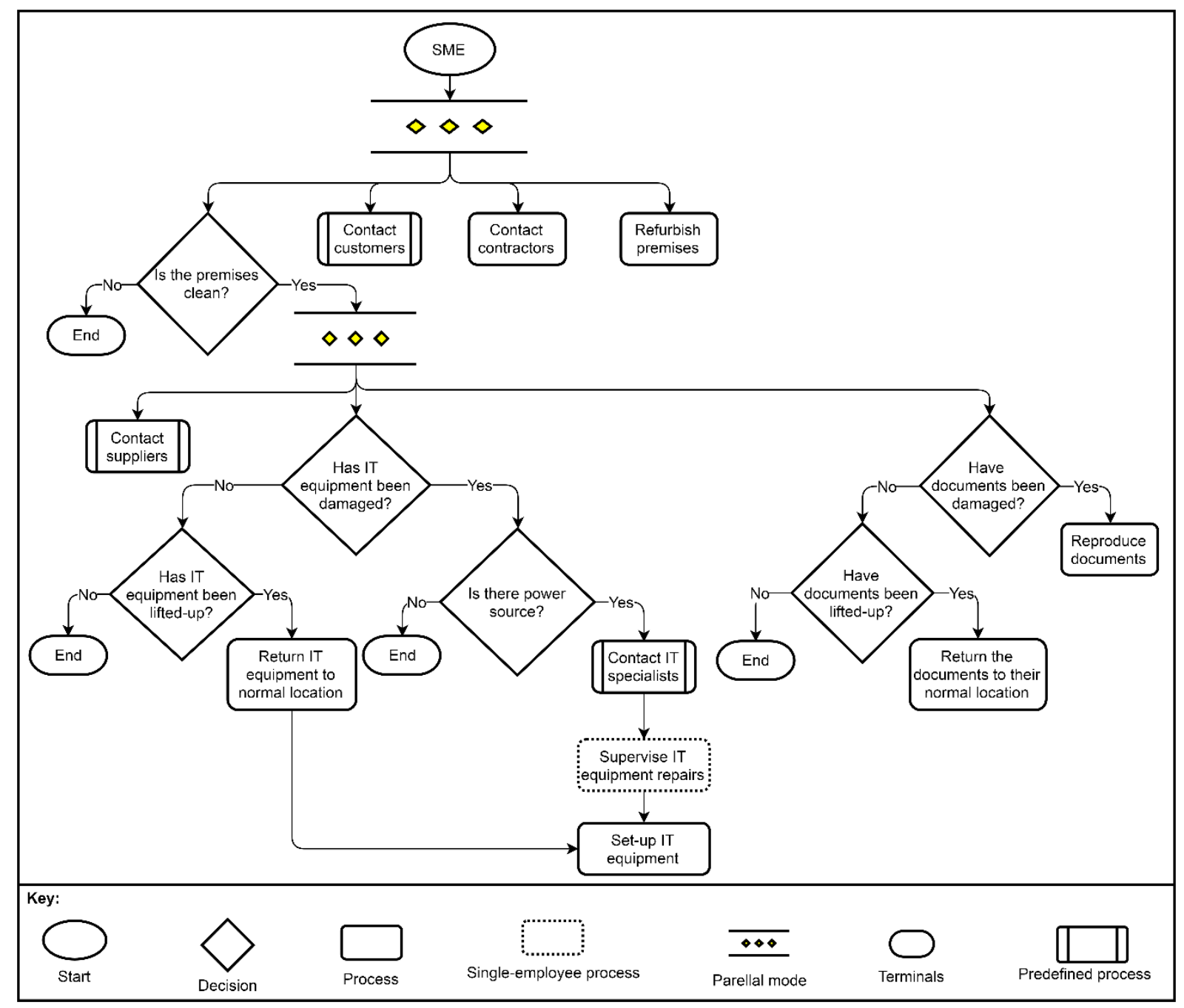

Figure A3: Post-flood behaviours of a manufacturing SME (3) 


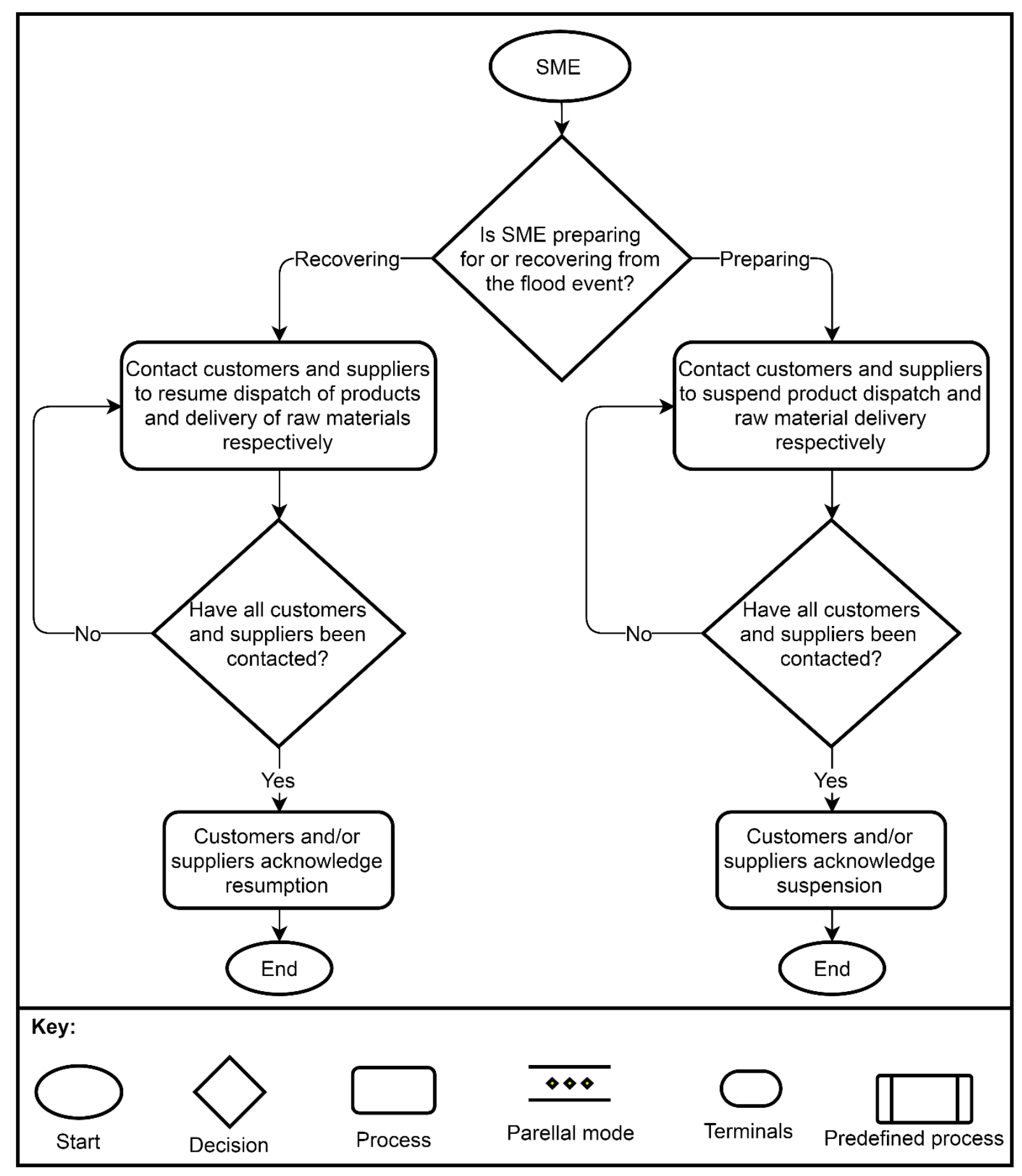

Figure A4: SME interaction with customers and suppliers 


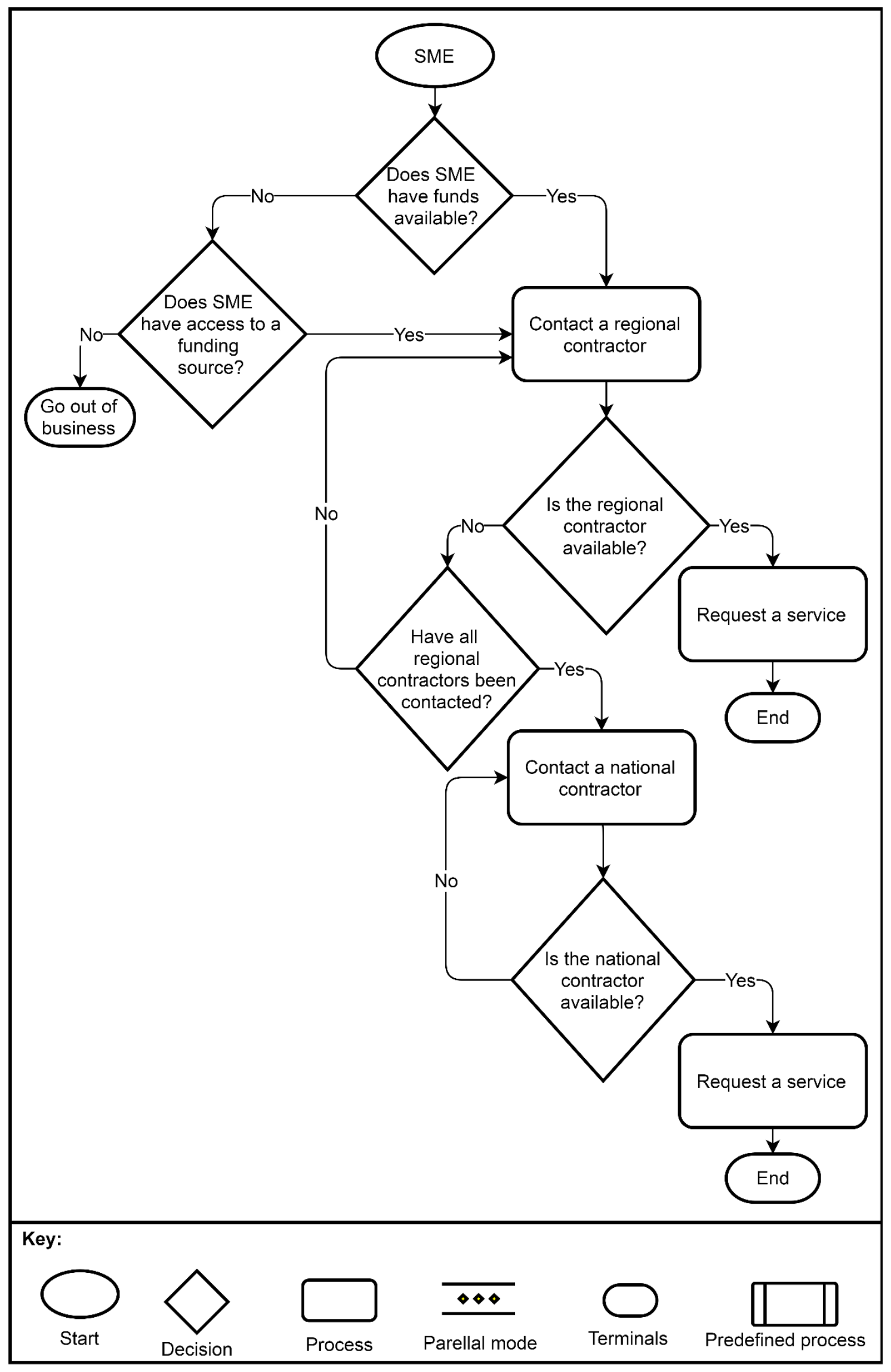

Figure A5: SME interaction with contractors 


\section{References}

Abar, S., Theodoropoulos, G. K., Lemarinier, P., \& O'Hare, G. (2017). Agent Based Modelling and Simulation tools: A review of the state-of-art software. Computer Science Review, 24, 13-33.

Allan, R. (2010). Survey of agent based modelling and simulation tools. Computational Science and Engineering Department, STFC Daresbury Laboratory, Warrington WA4 4AD. Retrieved from http://epubs.cclrc.ac.uk/epub/bitstream/5601/DLTR-2010-007.pdf

Arunachalam, S., \& Steiner, R. (2008). Environment mediated Multi Agent Simulation Tools - A Comparison 3 . Comparison Criteria 2 . The Tools. In Self-Adaptive and Self-Organizing Systems Workshops (pp. 1-6).

Arvitrida, N. I., Tako, A. A., Robertson, D. A., \& Robinson, S. (2017). Duration of collaboration from a market perspective: An agent-based modeling approach. Operation and Supply Chain Management Journal, 10(3), 149-159. Retrieved from http://www.journal.oscmforum.org/journal/issue/journals/oscm-volume-10-issue-3-2017

Bellamine-Ben Saoud, N., Ben Mena, T., Dugdale, J., Pavard, B., \& Ben Ahmed, M. (2006). Assessing large scale emergency rescue plans: an agent based approach. International Journal of Intelligent Control and Systems, 11(4), 260-271.

Best, N., \& Fraser, D. (2009). The summer 2007 floods: One year on and the lessons learned. Journal of Business Continuity \& Emergency Planning, 3(2), 132-136. Retrieved from http://search.ebscohost.com/login.aspx?direct=true\&db=bth\&AN=36917654\&site=ehost-live

Bhattacharya-Mis, N., \& Lamond, J. (2014). An investigation of patterns of response and recovery among flood-affected businesses in the UK: A case study in Sheffield and Wakefield. WIT Transactions on Ecology and the Environment, 184, 163-173. https://doi.org/10.2495/FRIAR140141

Blackmore, K., Bossomaier, T., Jarratt, D., \& Nesbitt, K. (2003). Intelligent Agent Framework for Modeling the Evolution of Small and Medium Sized Enterprises. In 8th Australian and New Zealand Conference on Intelligent Information Systems (pp. 345-350). Sydney, Australia.

Bonabeau, E. (2002). Agent-based modeling: methods and techniques for simulating human systems. Proceedings of the National Academy of Sciences, 99(suppl. 3), 7280-7287. https://doi.org/10.1073/pnas.082080899

British Standards Institution. (2012). ISO 22301 Societal security - Business continuity management systems - Requirements. BSI Standards Publication, 36. Retrieved from file://Users/waynemullins/Downloads/BSi BS ISO 223012012 Societal security. Business continuity management systems. Requirements 2012.pdf

Burstein, F. V., \& Gregor, S. (1999). The Systems Development or Engineering Approach to Research in Information Systems: An Action Research Perspective. In 10th Australasian Conference on Information Systems (pp. 122-124). Wellington, New Zealand.

CH2MHILL. (2015). ISIS 1D Quick Start Guide, (3.7). Retrieved from www.floodmodeller.com Chatterton, J., Clarke, C., Daly, E., Dawks, S., Elding, C., Fenn, T., ... R, S. (2016). The costs and impacts of the winter 2013 to 2014 floods. 
Chatterton, J., Viviattene, C., Morris, J., Penning-Rowsell, E. C., \& Tapsell, S. M. (2010). The costs of the summer 2007 floods in England. https://doi.org/978-1-84911-146-1

Coates, G., Hawe, G. I., McGuinness, M., Wright, N. G., Guan, D., Harries, T., \& McEwen, L. (2013). A framework for organisational operational response and strategic decision making for long term flood preparedness in urban areas. WIT Transactions on the Built Environment, 133, 89-98. https://doi.org/10.2495/DMAN130091

Confederation of British Industry. (2009). Future proof : Preparing your business for a changing climate Impacts on business are likely to be diverse.

Dawson, R. J., Peppe, R., \& Wang, M. (2011). An agent-based model for risk-based flood incident management. Natural Hazards, 59(1), 167-189. https://doi.org/10.1007/s11069-011-9745-4

DeLoach, S. A., Wood, M. F., \& Sparkman, C. H. (2001). Multiagent Systems Engineering. International Journal of Software Engineering and Knowledge Engineering, 11(3), 231-258. https://doi.org/10.1142/S0218194001000542

Dignum, V., \& Tick, C. (2007). Agent-based Analysis of Organizations: Formalization and Simulation. In Proceedings of the IEEE/WIC/ACM International Conference on Intelligent Agent Technology (pp. 244-247).

Du, E., Cai, X., Sun, Z., \& Minsker, B. (2017). Exploring the Role of Social Media and Individual Behaviors in Flood Evacuation Processes: An Agent-Based Modeling Approach. Water Resources Research, 53(11), 9164-9180. https://doi.org/10.1002/2017WR021192

Dubbelboer, J., Nikolic, J., Jenkins, K., Hall, J. (2017). An Agent-Based Model of Flood Risk and Insurance. Journal of Artificial Societies and Social Simulation, 20(1)(6). https://doi.org/10.18564/jasss.3135

Environment Agency. (2011). Review of 2007 summer floods. Environment, (December), 1-58.

Environment Agency. (2012). Flood estimation guidelines, (197), 1-119. Retrieved from http://persona.uk.com/A21Ton/Core_dox/H/H13.pdf

Environment Agency. (2017). http://www.environment-agency.gov.uk.

Evans, E. P., Simm, J. D., Thorne, C. R., Arnell, N. W., Ashley, R. M., Hess, T. M., .. Wheater, H. S. (2008). An update of the foresight future flooding 2004 qualitative risk analysis, (June), 159. Retrieved from http://eprints.soton.ac.uk/75728/

Fioretti, G. (2013). Agent-Based Simulation Models in Organization Science. Organizational Research Methods, 16(2), 227-242. https://doi.org/10.1177/1094428112470006

Fortino, G., Garro, A., \& Russo, W. (2005). An integrated approach for the development and validation of multi-agent systems. Computer Systems Science \& Engineering (CSSE), 20(4), 259-280.

Fortino, G., \& North, M. J. (2013). Simulation-based development and validation of multi-agent systems: AOSE and ABMS approaches. Journal of Simulation, 7(3), 137-143. https://doi.org/10.1057/jos.2013.12

Fortino, G., \& Russo, W. (2012). ELDAMeth: An agent-oriented methodology for simulation-based prototyping of distributed agent systems. Information and Software Technology, 54(6), 608-624. https://doi.org/10.1016/j.infsof.2011.08.006 
Fu, J., \& Fu, Y. (2015). An adaptive multi-agent system for cost collaborative management in supply chains. Engineering Applications of Artificial Intelligence, 44, 91-100.

https://doi.org/10.1016/j.engappai.2015.05.002

Gómez-Cruz, N. A., Loaiza Saa, I., \& Ortega Hurtado, F. F. (2017). Agent-based simulation in management and organizational studies: a survey. European Journal of Management and Business Economics, 26(3), 313-328. https://doi.org/10.1108/EJMBE-10-2017-018

Grunert, J., \& Norden, L. (2012). Bargaining power and information in SME lending. Small Business Economics, 39(2), 401-417.

Haer, T., Botzen, W. J. W., \& Aerts, J. C. J. H. (2016). The effectiveness of flood risk communication strategies and the influence of social networks-Insights from an agent-based model.

Environmental Science and Policy, 60(November 2017), 44-52.

https://doi.org/10.1016/j.envsci.2016.03.006

Harrison, A. R. (2006). National Land Use Database: Land Use and Land Cover Classification, Version 4.4, 81.

Hawe, G. I., Coates, G., Wilson, D. T., \& Crouch, R. S. (2015). Agent-based simulation of emergency response to plan the allocation of resources for a hypothetical two-site major incident.

Engineering Applications of Artificial Intelligence, 46, 336-345.

https://doi.org/10.1016/j.engappai.2015.06.023

Heath, B., Hill, R., \& Ciarallo, F. (2009). A survey of agent-based modeling practices (January 1998 to July 2008). Journal of Artificial Societies and Social Simulation, 12(9).

Herbane, B. (2010a). Small business research: Time for a crisis-based view. International Small Business Journal, 28(1), 43-64.

Herbane, B. (2010b). The evolution of business continuity management: A historical review of practices and drivers. Business History, 52(6), 978-1002.

Hooshangi, N., \& Alesheikh, A. (2018). Developing an Agent-Based Simulation System for PostEarthquake Operations in Uncertainty Conditions: A Proposed Method for Collaboration among Agents. ISPRS International Journal of Geo-Information, 7(1), 27.

https://doi.org/10.3390/ijgi7010027

Ingirige, B., \& Wedawatta, G. (2011a). Impacts of flood hazards on small and medium companies: strategies for property level protection and business continuity. In Flood Hazards, Impacts and Responses for the Built Environment (pp. 269-280).

Ingirige, B., \& Wedawatta, G. (2011b). SME resilience to extreme weather events: Important initiatives for informing policy making in the area. In International Conference on Building Resilience.

Retrieved from http://www.disaster-resilience.salford.ac.uk/resilientcities/

Jenkins, K., Surminski, S., Hall, J., \& Crick, F. (2017). Science of the Total Environment Assessing surface water fl ood risk and management strategies under future climate change : Insights from an Agent-Based Model. Science of the Total Environment, 595, 159-168.

https://doi.org/10.1016/j.scitotenv.2017.03.242

Jones, K., \& Ingirige, B. (2008). Extreme weather events and business continuity planning. In CIB W70 International Conference in Facilities Management. Edinburgh, Scotland. 
Kjeldsen, T. R., Stewart, E. J., Packman, J. C., Folwell, S. S., \& Bayliss, A. C. (2005). Revitalisation of the $\mathrm{FSR} / \mathrm{FEH}$ rainfall runoff method.

Klügl, F. (2008). A validation methodology for agent-based simulations. Proceedings of the 2008 ACM Symposium on Applied ..., 39-43. https://doi.org/10.1145/1363686.1363696

Kravari, K., \& Bassiliades, N. (2015). A Survey of Agent Platforms. Journal of Artificial Societies and Social Simulation, 18(1).

Li, C., Coates, G., Johnson, N., \& Mcguinness, M. (2015). Designing an Agent-Based Model of SMEs to Assess Flood Response Strategies and Resilience. International Journal of Social, Behavioural, Educational, Economic and Management Engineering, 9(1), 7-12. Retrieved from http://waset.org/publications/10000097/designing-an-agent-based-model-of-smes-to-assessflood-response-strategies-and-resilience

Lin, B., Wicks, J. M., Falconer, R. A., \& Adams, K. (2006). Integrating 1D and 2D hydrodynamic models for flood simulation. Proceedings of the Institution of Civil Engineers - Water Management, 159(1), 19-25.

Liu, Y., Okada, N., Shen, D., \& Li, S. (2010). Agent-based Flood Evacuation Simulation of Lifethreatening Conditions Using Vitae System Model. Journal of Natural Disaster Science, 31(2), 33-41.

McGuinness, M., \& Johnson, N. (2013). Responding to changing paradigms of risk: managing flood risk and enhancing organisational resilience. In Association of Geographical Societies in Europe (EUGEO) 2013 Congress, "Changing Geographies and Geographies of Change." Rome, Italy.

Mysore, V., Narzisi, G., \& Mishra, B. (2006). Agent Modeling of a Sarin Attack in Manhattan. In Proceedings of the 1st International Workshop on Agent Technology for Disaster Management in the 5th International Conference on Autonomous Agents and Multi-Agent Systems (pp. 108115).

Niazi, M. A. K. (2011). Towards A Novel Unified Framework for Developing Formal, Network and Validated Agent-Based Simulation Models of Complex Adaptive Systems, 275.

Nikolai, C., \& Madey, G. (2009). Tools of the Trade: A Survey of Various Agent Based Modeling Platforms. Journal of Artificial Societies and Social Simulation, 12(2).

North, M. J. (2005). The repast simphony development environment, 159-166.

North, M. J., Collier, N. T., Ozik, J., Tatara, E. R., Macal, C. M., Bragen, M., \& Sydelko, P. (2013). Complex adaptive systems modeling with Repast Simphony, 1-26.

North, M. J., Collier, N. T., \& Vos, J. R. (2006). Experiences Creating Three Implementations of the Repast Agent Modeling Toolkit, 16(1), 1-25.

North, M. J., \& Macal, C. M. (2007). Managing business complexity: discovering strategic solutions with agent-based modeling and simulation. Oxford University Press.

Pablo-Marti, F., Gallo, M. T., Garcia-Tabuenca, A., Santos, J. L., \& T. Mancha. (2012). MOSIPS Agent-based model for predicting and simulating the impact of public policies on SMEs. In European Conference on Complex Systems (pp. 399-413).

Pitt, M. (2008). Learning Lessons from the 2007 Floods. Floods Review, 1-205. https://doi.org/10.1007/s13398-014-0173-7.2 
Railsback, S. F., Lytinen, S. L., \& Jackson, S. K. (2006). Agent-based Simulation Platforms: Review and Development Recommendations. Simulation, 82(9), 609-623.

https://doi.org/10.1177/0037549706073695

Reuter, C. (2015). Towards Efficient Security: Business Continuity Management in Small and Medium Enterprises. International Journal of Information Systems for Crisis Response and Management, 7(3), 69-79.

Rhodes, C. (2016). Business statistics, (6152), 5. Retrieved from researchbriefings.files.parliament.uk/documents/SN06152/SN06152.pdf

Rickard, C. E. (2009). Floodwalls and flood embankments. Fluvial Design Guide, 1-29.

Robertson, D. A. (2005). Agent-Based Models to Manage the Complex. In Managing the Complex (pp. 471-430).

Salamon, T. (2011). Design of Agent-Based Models: Developing Computer Simulations for a Better Understanding of Social Processes. Bruckner Publishing.

Sauser, B., Baldwin, C., Pourreza, S., Randall, W., \& Nowicki, D. (2017). Resilience of small- and medium-sized enterprises as a correlation to community impact: an agent-based modeling approach. Natural Hazards, 90(1), 1-21. https://doi.org/10.1007/s11069-017-3034-9

Sterling, S. (2011). Encouraging resilience within SMEs: The Cabinet Office's proposed approach. Journal of Business Continuity \& Emergency Planning, 5(2), 128-139. https://doi.org/10.1111/ijmr.12076

Sullivan-Taylor, B., \& Branicki, L. (2011). Creating resilient SMEs: why one size might not fit all. International Journal of Production Research, 49(18), 5565-5579.

The UK Cabinet Office. (2015). National Risk Register of Civil Emergencies. National Risk Register of Civil Emergencies, 1-58. Retrieved from https://www.gov.uk/government/collections/nationalrisk-register-of-civil-emergencies

Tobias, R., \& Hofmann, C. (2004). Evaluation of free Java-libraries for social-scientific agent based simulation. Journal of Artificial Societies and Social Simulation, 7(1), 1-6.

Tonn, G. L., \& Guikema, S. D. (2017). An Agent-Based Model of Evolving Community Flood Risk. Risk Analysis. https://doi.org/10.1111/risa.12939

Tounsi, J., Habchi, G., Boissiere, J., \& Azaiez, S. (2012). A multi-agent knowledge model for SMEs mechatronic supply chains. Journal of Intelligent Manufacturing, 23(6), 2647-2665. https://doi.org/10.1007/s10845-011-0537-1

TUFLOW. (2016). TUFLOW User Manual. Retrieved from www.tuflow.com

Van Gils, A. (2005). Management and governance in Dutch SMEs. European Management Journal, 23(5), 583-589.

Wang, M., Wang, H., Vogel, D., Kumar, K., \& Chiu, D. K. W. (2009). Agent-based negotiation and decision making for dynamic supply chain formation. Engineering Applications of Artificial Intelligence, 22(7), 1046-1055. https://doi.org/10.1016/j.engappai.2008.09.001

Wedawatta, G., \& Ingirige, B. (2012). Resilience and adaptation of small and medium-sized enterprises to flood risk. Disaster Prevention and Management: An International Journal, 21(4), 474-488. https://doi.org/10.1108/09653561211256170 
Wedawatta, G., Ingirige, B., \& Proverbs, D. (2014). Small businesses and flood impacts: The case of the 2009 flood event in Cockermouth. Journal of Flood Risk Management, 7(1), 42-53. https://doi.org/10.1111/jfr3.12031

Wilkinson, I. F., Young, L., Marks, R., Bossomaier, T., \& Held, F. P. (2011). Toward a Business Network Agent-Based Modeling System. In International Conference on Complex Systems (pp. 680-691).

Wilkinson, I., Marks, R., \& Young, L. (2010). Toward agent-based models of the development and evolution of business relations and networks. In Unifying Themes in Complex Systems - Volume VI: Proceedings of the 6th International Conference on Complex Systems (pp. 414-421). Retrieved from http://link.springer.com/chapter/10.1007/978-3-540-85081-6_51

Yang, L. E., Scheffran, J., Süsser, D., Dawson, R., \& Chen, Y. D. (2018). Assessment of Flood Losses with Household Responses: Agent-Based Simulation in an Urban Catchment Area. Environmental Modeling and Assessment, 1-20. https://doi.org/10.1007/s10666-018-9597-3

Zobel, C. (2010). Comparative Visualization of Predicted Disaster Resilience. Seventh International ISCRAM Conference, (May), 1-6.

Zobel, C. (2011). Representing perceived tradeoffs in defining disaster resilience. Decision Support Systems, 50(2), 394-403. https://doi.org/10.1016/j.dss.2010.10.001 